\title{
A meteorological overview of the MILAGRO field campaigns
}

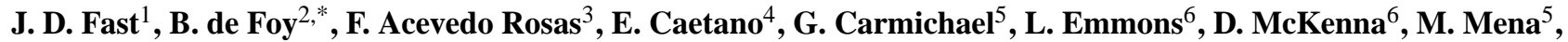 \\ W. Skamarock ${ }^{6}$, X. Tie ${ }^{6}$, R. L. Coulter ${ }^{7}$, J. C. Barnard ${ }^{1}$, C. Wiedinmyer ${ }^{6}$, and S. Madronich ${ }^{6}$ \\ ${ }^{1}$ Pacific Northwest National Laboratory, Richland, WA, USA \\ ${ }^{2}$ Molina Center for Energy and the Environment, La Jolla, CA, USA \\ ${ }^{3}$ Comisión Nacional del Agua, USMN-GRGC, Boca del Río, Veracruz, México \\ ${ }^{4}$ Centro de Ciencias de la Atmósfera, Universidad Nacional Autónoma de México, México City, México \\ ${ }^{5}$ University of Iowa, Iowa City, IA, USA \\ ${ }^{6}$ National Center for Atmospheric Research, Boulder, CO, USA \\ ${ }^{7}$ Argonne National Laboratory, Argonne, IL, USA \\ * now at: Saint Louis University, Saint Louis, MO, USA
}

Received: 11 December 2006 - Published in Atmos. Chem. Phys. Discuss.: 13 February 2007

Revised: 17 April 2007 - Accepted: 19 April 2007 - Published: 3 May 2007

\begin{abstract}
We describe the large-scale meteorological conditions that affected atmospheric chemistry over Mexico during March 2006 when several field campaigns were conducted in the region. In-situ and remote-sensing instrumentation was deployed to obtain measurements of wind, temperature, and humidity profiles in the boundary layer and free atmosphere at four primary sampling sites in central Mexico. Several models were run operationally during the field campaign to provide forecasts of the local, regional, and synoptic meteorology as well as the predicted location of the Mexico City pollutant plume for aircraft flight planning purposes. Field campaign measurements and large-scale analyses are used to define three regimes that characterize the overall meteorological conditions: the first regime prior to 14 March, the second regime between 14 and 23 March, and the third regime after 23 March. Mostly sunny and dry conditions with periods of cirrus and marine stratus along the coast occurred during the first regime. The beginning of the second regime was characterized by a sharp increase in humidity over the central plateau and the development of late afternoon convection associated with the passage of a weak cold surge on 14 March. Over the next several days, the atmosphere over the central plateau became drier so that deep convection gradually diminished. The third regime began with the passage of a strong cold surge that lead to humidity, afternoon convection, and precipitation over the central plateau that was higher than during the second regime. The frequency and intensity of fires, as determined by satellite
\end{abstract}

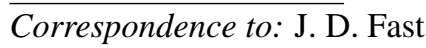

(jerome.fast@pnl.gov) measurements, also diminished significantly after the third cold surge. The synoptic-scale flow patterns that govern the transport of pollutants in the region are described and compared to previous March periods to put the transport into a climatological context. The complex terrain surrounding Mexico City produces local and regional circulations that govern short-range transport; however, the mean synoptic conditions modulate the thermally-driven circulations and on several days the near-surface flow is coupled to the ambient winds aloft.

\section{Introduction}

The rapid growth of megacities has led to serious urban air pollution problems in many developing countries. For example, Mexico City is the largest metropolitan area in North America with a population of $\sim 20$ million. In addition to the sources of trace gases and aerosols resulting from human activities, the local meteorological conditions influenced by the surrounding terrain strongly affect the poor air quality that is observed. As shown in Fig. 1, Mexico City is located within a basin on the central Mexican plateau at an elevation of $\sim 2200 \mathrm{~m}$ above sea level (m.s.l.) at $\sim 19.4 \mathrm{~N}$ latitude. Mountain ranges that are $\sim 1000 \mathrm{~m}$ higher than the basin floor border the west, south, and east sides of the city. The mountain ranges include several tall peaks, the tallest being the Popocatepetl volcano located southeast of Mexico City with an elevation of $5465 \mathrm{~m}$ m.s.l. The gap in the mountains at the southeast end of the basin also affects the local

Published by Copernicus GmbH on behalf of the European Geosciences Union. 


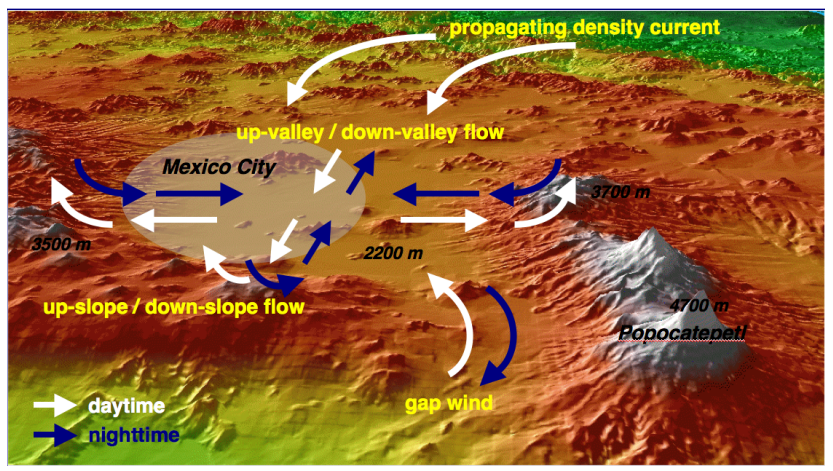

Fig. 1. Schematic diagram depicting types of thermally-driven flows that have been observed in the vicinity of Mexico City. White and blue arrows denote daytime and nighttime wind directions, respectively. Topography elevation $(\mathrm{m})$ at select locations denoted by black text.

basin circulations (Doran and Zhong, 2000; Jazcilevich et al., 2003; de Foy et al., 2006a).

The generally light synoptic winds, subtropical and highaltitude insolation, formation of shallow stable boundary layers at night, and boundary-layer circulations influenced by the complex terrain (Jáuregui, 1988; Lauer and Klaus, 1975) combine to produce frequent episodes with elevated levels of ozone and particulate matter during the entire year (Collins and Scott, 1993; Garfias and Gonzolas, 1992; Raga et al., 2001). The thermal and dynamic effects of urbanization also modify boundary layer properties (Jáuregui, 1997; Oke et al., 1999) and subsequently near-surface transport and mixing of pollutants. In addition to anthropogenic sources, particulate concentrations are influenced by dust (Edgerton et al., 1999; Vega et al., 2002) and sulfate produced downwind of Popocatepetl (Raga et al., 1999b) and the Tula refinery complex (Johnson et al., 2006). Measurements of cloud condensation nuclei $(\mathrm{CCN})$ concentrations are linked to particulate concentrations in Mexico City (Baumgardner et al., 2004), suggesting that anthropogenic sources may alter local precipitation (Jáuregui and Romales, 1996).

As a result of several recent field campaigns, much is known about the boundary layer evolution and transport processes in the immediate vicinity of Mexico City that affect trace gases and aerosols. Meteorological and chemical measurements made over the southern mountain range during the 1997 Azteca experiment indicated that up-slope flows transported pollutants out of the city to higher elevations during the day, and down-slope flows transported a portion of the pollutants back towards the city at night (Raga et al., 1999a; Baumgardner et al., 2000). A mesoscale model predicted the development of a propagating density current during the 1991 Mexico City Air Quality Research Initiative (MARI) resulting from the horizontal temperature gradient between the warmer basin atmosphere and cooler marine air east of the Sierra Madre Oriental along the Gulf of Mexico (Bossert, 1997); however, there were relatively few measure- ments to provide direct observational evidence of the circulation. Measurements from four meteorological profiling sites consisting of radar wind profilers and radiosondes during the 1997 Investigacion sobre Materia Particulada y Deterioro Atmosferico-Aerosol and Visibility Research (IMADAAVER) field campaign (Doran et al., 1998; Edgerton et al., 1999) showed that propagating density currents frequently produced strong near-surface northerly flows, lower temperatures, and higher humidity over the northern basin. Based on the meteorological profiles, Whiteman et al. (2000) found the boundary layer evolution and regional flows were determined primarily by the plateau topography; however, somewhat more heating and cooling in Mexico City resulted from the basin topography. Strong southeasterly flow in the form of a low-level jet through the terrain gap in the southeastern corner of the basin was observed to develop frequently during IMADA-AVER as a result of the horizontal temperature gradient between the warmer basin atmosphere and cooler free atmosphere to the south (Doran and Zhong, 2000). Surface wind measurements over the city indicated that the opposing propagating density current and gap flow produces strong convergence in the basin during the late afternoon. Routine and special measurements made during the 2003 Mexico City Metropolitan Area (MCMA-2003) field campaign showed that the location of the largest ozone concentrations in the city depended on the interaction of the synoptic conditions and local thermally-driven flows (de Foy et al., 2005). Downward momentum flux was also found to influence the evolution of the convergence zone (de Foy et al., 2006a). Dispersion modeling studies (Fast and Zhong, 1998; de Foy et al., 2006b; Jazcilevich et al., 2005) have shown that the near-surface convergence and other thermally-driven flows can effectively ventilate pollutants out of the basin and reduce the likelihood of multi-day accumulation of pollutants. A schematic diagram depicting the various thermallydriven flows that have been observed in the vicinity of Mexico City is shown in Fig. 1.

Conversely, there have been very few meteorological and chemical measurements in the surrounding region that can be used to describe the fate of pollutants originating from Mexico City. In addition to affecting regional air quality, aerosols originating from Mexico City may also impact the local and regional climate by altering the radiation budget (Jauegui and Luyando, 1999; Raga et al., 2001). To better understand the evolution of trace gases and particulates originating from anthropogenic emissions in Mexico City and their impact on regional air quality and climate, a field campaign called the Megacities Initiative: Local And Global Research Observations (MILAGRO) collected a wide range of meteorological, chemical, and particulate measurements during March 2006. Measurements were also obtained over a wide range of spatial scales from local, regional, and large-scale field experiments to describe the evolution of the Mexico City pollutant plume from its source and up to several hundred kilometers downwind. 

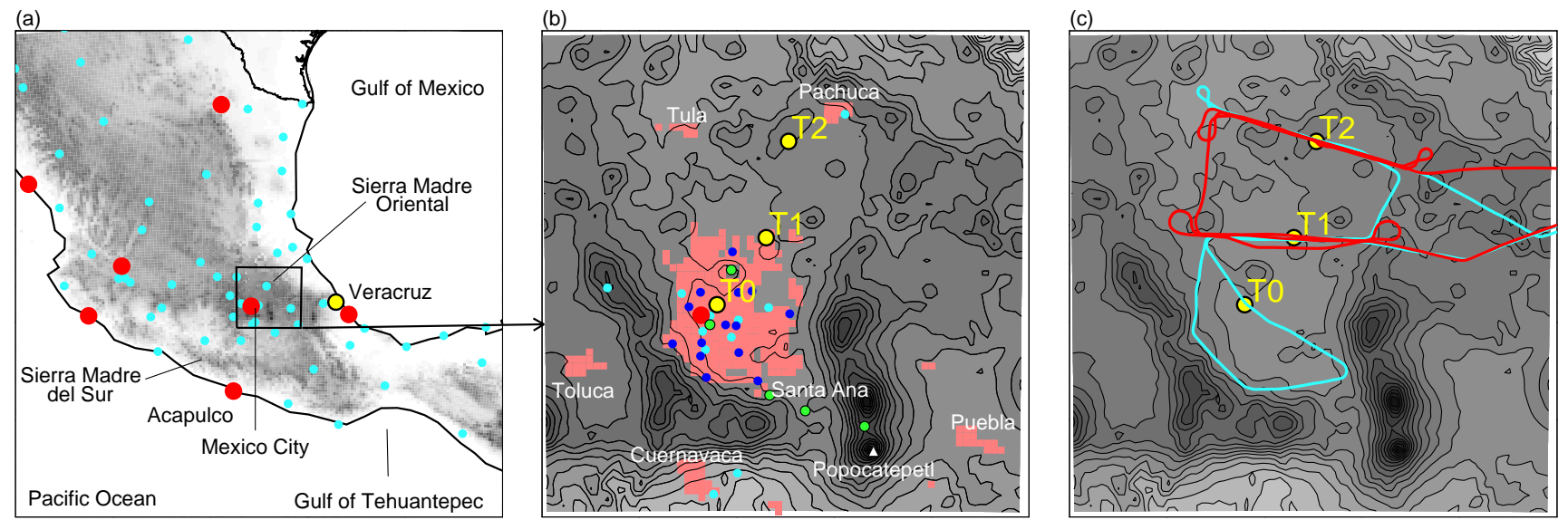

Fig. 2. Locations of various measurement sites during the MILAGRO field campaigns including (a) operational rawinsonde (red dots) and surface meteorological sites (light blue dots) over Mexico, (b) operational surface meteorological sites (light blue dots), operational air quality and meteorology sites (dark blue dots), MILAGRO super-sites (yellow dots), and other MILAGRO sites (green) in the vicinity of Mexico City, and (c) typical aircraft flight paths over the surface sampling sites by the G-1 aircraft during the morning (blue) and afternoon (red). Light red shading denotes urban areas and gray shading denotes topography, with contour intervals of $200 \mathrm{~m}$ in (b) and (c).

MILAGRO was composed of five collaborative field experiments. The MCMA-2006 field experiment, supported by various Mexican institutions and the U.S. National Science Foundation (NSF) and Department of Energy (DOE), obtained measurements at several surface sites over the city. Measurements in the city and regional measurements up to a hundred kilometers downwind of the city were obtained from the G-1 and B200 aircraft during the Megacities Aerosol Experiment (MAX-Mex) supported by the DOE. The Megacities Impact on Regional and Global Environments - Mexico (MIRAGE-Mex) field experiment, supported by the NSF and Mexican agengies, obtained regional and large-scale measurements up to several hundred kilometers downwind of Mexico City using the C-130 aircraft. Large-scale measurements downwind of Mexico City as far as the northern Gulf of Mexico were collected by the DC- 8 and J31 aircraft during the Intercontinental Transport Experiment B (INTEX-B), supported by the National Aeronautical and Space Administration (NASA). Finally, a Twin Otter aircraft was used to sample biomass burning smoke plumes in central Mexico, with support from the USDA Forest Service and the NSF.

In this study we describe the rationale for the meteorological sampling strategy that was developed for MILAGRO, the forecasting activities that supported the research aircraft sampling, and the synoptic meteorological conditions observed during the field campaign. Large-scale meteorological analyses, routine surface and satellite data, and MILAGRO meteorological measurements are employed to describe the synoptic conditions influencing the transport, transformation, and fate of atmospheric trace gases and aerosols downwind of Mexico City.

\section{Meteorological sampling}

Operational meteorological measurements in Mexico are relatively sparse compared to the U.S. Figure 2 a shows the locations of the rawinsondes that obtain vertical profiles of pressure, temperature, humidity, and winds and shows the locations of surface meteorological stations operated by the Servicio Meteorológico Nacional (SMN). Rawinsondes are launched twice per day from Mexico City at 00:00 and 12:00 UTC, but only once per day at 00:00 UTC at the remaining sites. These soundings are assimilated into $\mathrm{Na}-$ tional Center for Environmental Prediction (NCEP) operational models to produce synoptic-scale analyses that are also the initial conditions for multi-day forecasts. Since most soundings are made only once per day, the synoptic-scale analyses at 06:00, 12:00, and 18:00 UTC may contain larger uncertainties over Mexico than at 00:00 UTC. Therefore, the rawinsonde network was supplemented so that soundings were made four times per day at 00:00, 06:00, 12:00 and 18:00 UTC at Mexico City, Veracruz, and Acapulco. The goal was to improve the synoptic-scale analyses in the region so that operational NCEP and MILAGRO model forecasts (described in Sect. 3) would be more accurate.

The month of March was selected for the field campaign period because of the dry, mostly sunny conditions observed over Mexico at this time of the year (Jáuregui, 2000). Clouds and precipitation that would complicate aircraft sampling and scavenge a portion of the pollutants in the region usually increase during April. To achieve the scientific goals of MILAGRO, the surface sampling sites needed to be located on the central plateau within a hundred kilometers of Mexico City. Farther downwind along the coast, the pollutant plume would likely become decoupled from the marine 
boundary layer and surface instrumentation located in that region would likely sample pollutants primarily from local sources. The aircraft flight tracks also needed to pass over the surface sites so that Mexico City pollutant plume could be sampled both at the surface and at multiple altitudes at the same time.

Therefore, the MILAGRO modeling working group conducted a series of studies prior to the field campaign to determine the primary regional and long-range transport pathways downwind of Mexico City, to help select the location of surface sampling sites, and to design aircraft sampling flight tracks. These studies used trajectories computed from historical synoptic-scale analyses and the HYSPLIT model (Draxler and Rolph, 2003) for February and March of 2002 and 2003, additional analysis of dispersion simulations described in Fast and Zhong (1998) and de Foy et al. (2006b) for February-March 1997 and April 2003, and regional chemistry simulations for select multi-day periods for meteorological conditions in March 1997 and 2005. The results suggested that the Mexico City pollutant plume is transported northeastward 20-30\% of the time during March. There was no preferred direction for the remaining time during March.

The principal surface sampling sites in the vicinity of Mexico City selected by MILAGRO scientists are shown in Fig. 2b. The T0 site, located in the northwestern part of the basin, was selected to measure fresh pollutants representative of the Mexico City metropolitan area. The T1 site, located just north of the basin, was selected to measure a mixture of fresh and aged pollutants as they exit the metropoli$\tan$ area. The T2 site, located about $35 \mathrm{~km}$ northeast of T1, was selected to measure aged pollutants as they are transported from Mexico City towards the northeast into the regional environment. The site names were derived from the sampling strategy to measure polluted air over the city and then at two times downwind during periods of southwesterly flow. An example of G-1 aircraft flight tracks is shown in Fig. 2c that depicts sampling aloft over the three principal sites and across the Mexico City pollutant plume during transport towards the northeast. The B200 and C-130 aircraft also frequently sampled over the surface measurements sites. Figure $2 b$ also shows the location of the routine air quality monitoring sites as well as special meteorological, chemical, and particulate measurement sites deployed as part of the MCMA-2006 experiment and experiments lead by scientists from the Universidad Nacional Autónoma de México (UNAM) and Insituto Mexicano del Petróleo (IMP) scientists.

In addition to the wide range of chemical and particulate instrumentation, meteorological instrumentation was deployed at T0, T1, and T2 to measure the evolution of wind fields and boundary layer properties that affect the vertical mixing, transport, and transformation of pollutants. Radar wind profilers at each site obtained wind speed and direction profiles up to $4 \mathrm{~km}$ a.g.l. at half hour intervals. A radar wind profiler was also deployed at Veracruz, located on the Gulf of Mexico east of Mexico City to obtain wind information aloft farther downwind of Mexico City. The wind profiles obtained at Veracruz extended as much as $1.5 \mathrm{~km}$ above the elevation of the central Mexican plateau. Several radiosondes were launched from $\mathrm{T} 1$ and $\mathrm{T} 2$ on G-1 research aircraft sampling days to obtain temperature and humidity profiles that characterize boundary layer growth and once per day on days when there were no G-1 flights. Some of these radiosondes also obtained wind profiles that extended above the radar wind profilers measurements. Temperature and humidity profiles at $\mathrm{T} 0$ were obtained at 1 -min intervals up to $10 \mathrm{~km}$ a.g.l. from a microwave radiometer (Karan and Knupp, 2006). A micro-pulse lidar (Campbell et al., 2002) and tethersondes were also deployed at $\mathrm{T} 0$ and $\mathrm{T} 1$ to obtain additional information on boundary layer properties.

\section{Operational forecasting}

A team of modelers produced daily weather briefings during the field campaign that consisted of current and forecasted meteorological conditions as well as the likely location of the Mexico City pollutant plume. These briefings, presented to scientists located at the Veracruz center of operations, were designed to contain information needed to plan and coordinate aircraft flight plans several days in advance. While NASA's DC-8 aircraft was deployed at Houston, the other five research aircraft were based at Veracruz. Veracruz's sea-level location permitted larger instrument payloads than would be possible at airports located on the plateau. Consequently, a large fraction of the aircraft operation scientists were located in Veracruz.

In addition to operational meteorological information such as satellite images and NCEP model forecasts products, the modeling team relied on real-time data from the radar wind profiler network and the micro-pulse lidar at $\mathrm{T} 1$ for current information on the winds and boundary layer depth over the central plateau. Several research models, listed in Table 1, were run during the field campaign to forecast the position of the Mexico City pollutant plume as well as regional and synoptic variations in the distribution of trace gases and aerosols. Individual models produced a combination of meteorology, dispersion, chemistry, or particulate forecasts. The resolution and domain size varied among the models, so that some models could resolve the local meteorology and chemistry in the vicinity of Mexico city while other models that did not resolve the spatial variations over the Mexican plateau were appropriate for use at synoptic-scales.

Two versions of the MM5 model (Grell et al., 1993) and two versions of the Weather Research and Forecasting (WRF) model (Skamarock et al., 2005) were used for the local and regional meteorological predictions over central Mexico. The meteorological fields from one version of MM5 were used to drive FLEXPART (de Foy et al., 2006b) 
Table 1. Operational forecasting models during MILAGRO.

\begin{tabular}{llllllll}
\hline Model Name & Organization & Scale & $\begin{array}{l}\text { Horizontal } \\
\text { Grid Spacing }\end{array}$ & Meteorology & Dispersion & Chemistry & Particulates \\
\hline MM5/FLEXPART & MCE2 $^{1}$ & local-regional & $12,36 \mathrm{~km}$ & $\times$ & $\times$ & & \\
MM5/MCCM & UNAM $^{2}$ & local-regional & $8,24 \mathrm{~km}$ & $\times$ & & $\times$ & \\
WRF & NCAR $^{3}$ & local-reginal-synoptic & $3,9 \mathrm{~km}$ & $\times$ & $\times$ & & $\times$ \\
WRF-CHEM & NCAR $^{3}$ & regional & $6 \mathrm{~km}$ & & & $\times$ & $\times$ \\
STEM & $\mathrm{UI}^{4}$ & regional - synoptic & $12,60 \mathrm{~km}$ & & $\times$ & \\
MOZART & $\mathrm{NCAR}^{3}$ & synoptic & $\sim 0.7$ degree & & $\times$ & \\
FLEXPART/ & NILU $^{5}$ & synoptic & $\sim 1$ degree & & & \\
ECMWF & & & & & & \\
RAQMS & NASA $^{6}$ & synoptic & $\sim 2$ degree & & & \\
GEOS-CHEM & Harvard $^{7}$ & synoptic & $50 \mathrm{~km}$ & & & \\
\hline
\end{tabular}

${ }^{1}$ Molina Center for Energy and the Environment

${ }^{2}$ Universidad Nacional Autonoma de Mexico

${ }^{3}$ National Center for Atmospheric Research

${ }^{4}$ University of Iowa

${ }^{5}$ Norwegian Institute for Air Research

${ }^{6}$ National Aeronautics and Space Administration

${ }^{7}$ Harvard University

and produce trajectory and particle dispersion predictions from multiple sources, while the other version of MM5 was used to drive the MCCM air quality model (Jazcilevich et al., 2003) and produce ozone forecasts within the Mexico City basin. Several passive scalars were added to one version of WRF to simulate the dispersion of pollutants emitted from Mexico City as a function of time. Another version of WRF was used to drive the STEM chemical-transport model (Carmichael et al., 2003) that made regional and synoptic-scale forecasts of chemistry and particulate matter from anthropogenic and biomass burning sources. A new, fully-coupled meteorology-chemistry-particulate model (WRF-chem) (Grell et al., 2005) was used to predict regional evolution of trace gases and aerosols. Synoptic-scale predictions of particle dispersion were made by the global version of FLEXPART (Stohl et al., 2005). The MOZART (Horowitz et al., 2003), RAQMS (Pierce et al., 2003), and GEOS-CHEM (Bey et al., 2001) models were used to predict synoptic-scale variations in trace gas chemistry. The special operational modeling products provided useful guidance, since most of the aircraft flights successfully sampled the Mexico City pollutant plume as planned. All MILAGRO investigators had access to the model forecast products, meteorological data, and weather briefings through a central internet site (http://catalog.eol.ucar.edu/milagro/).

Most of the initial and boundary conditions of meteorology for the local and regional-scale models were based on NCEP's Global Forecasting System (GFS) analyses and forecasts. One objective of launching additional soundings at Mexico City, Veracruz and Acapulco was that the GFS analyses would be improved over Mexico and these analyses would subsequently improve the forecasts made by the MILAGRO models. Because of the importance of the GFS analyses, the next section also discusses some of the similarities and differences between the GFS analyses and the radar wind profiler and rawinsonde measurements.

\section{Synoptic-scale winds aloft}

Clear skies, low humidity, and weak winds aloft associated with high-pressure systems are usually observed over Mexico during March. Upper-level low-pressure troughs occasionally propagate over Mexico producing stronger westerly to southwesterly winds and increased cloudiness. The synoptic-scale conditions control the long-range transport of pollutants downwind of Mexico City, but they also affect the development of thermally-driven circulations and subsequently the local and regional transport, mixing, and transformation of trace gases and particulate matter released from Mexico City and other sources on the central plateau (e.g. de Foy et al., 2006a; Fast and Zhong ,1998).

The $700 \mathrm{hPa}$ wind and geopotential height fields at 12:00 UTC every other day during March 2006 are shown in Fig. 3 to illustrate the evolving synoptic conditions during MILAGRO. While the $700 \mathrm{hPa}$ level is $\sim 3200 \mathrm{~m}$ above sea level, it is only $\sim 1000 \mathrm{~m}$ above the ground over Mexico City. During the first part of the field campaign between 1 and 8 March (Figs. 3a-d), high pressure at $700 \mathrm{hPa}$ slowly 


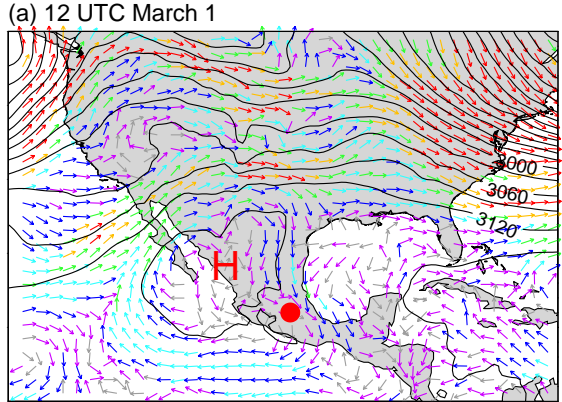

(d) 12 UTC March 7

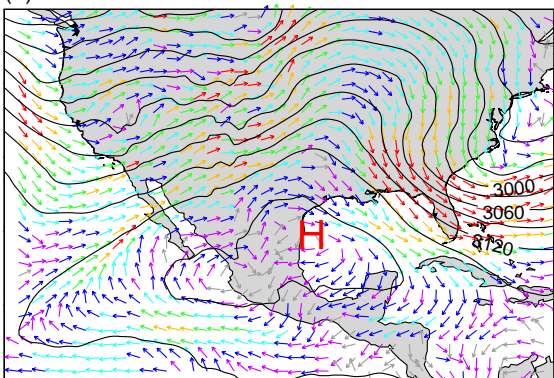

(g) 12 UTC March 13
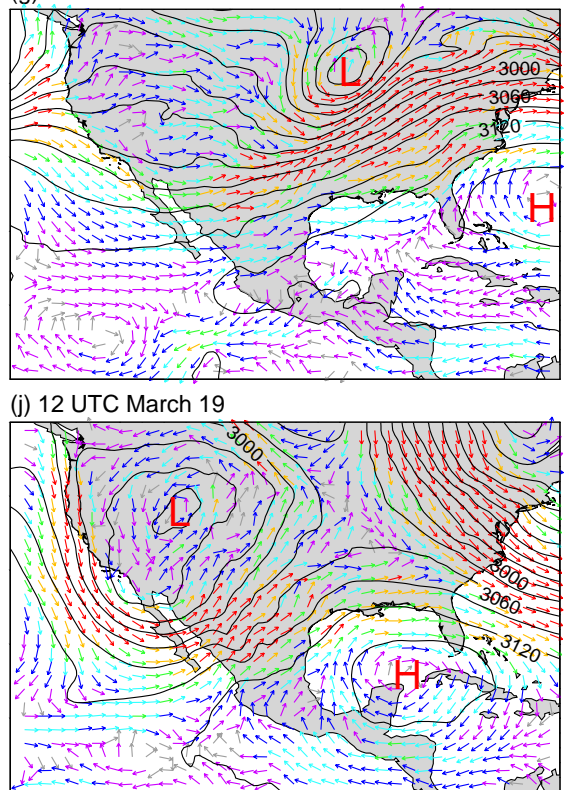

(m) 12 UTC March 25

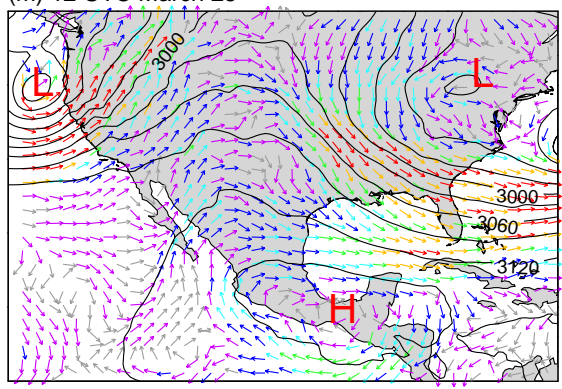

$3-6$ (b) 12 UTC March 3

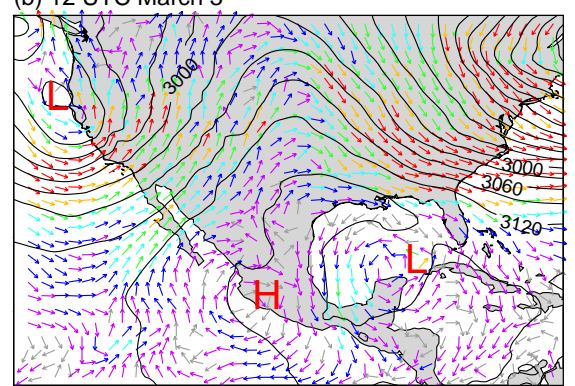

(e) 12 UTC March 9

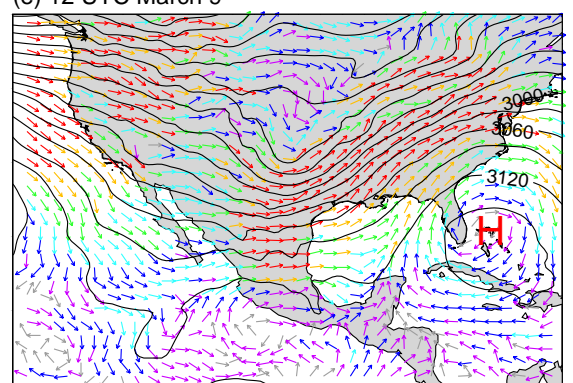

(h) 12 UTC March 15

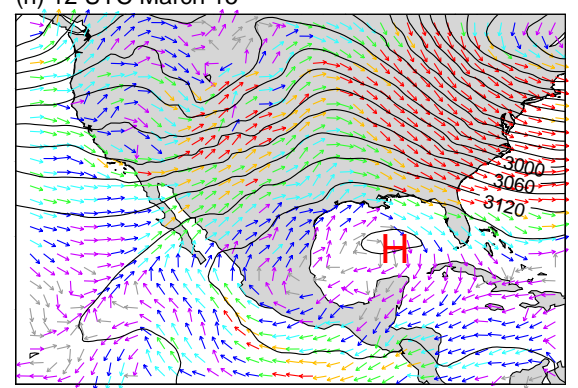

(k) 12 UTC March 21

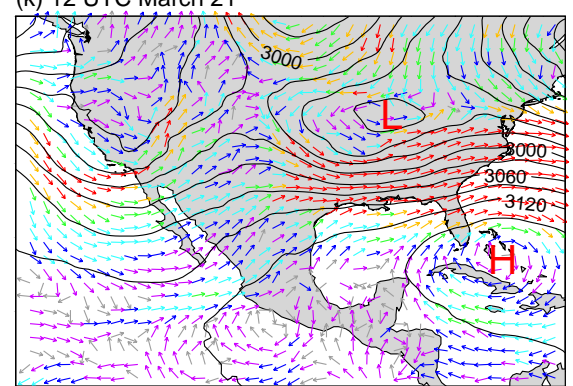

(n) 12 UTC March 27

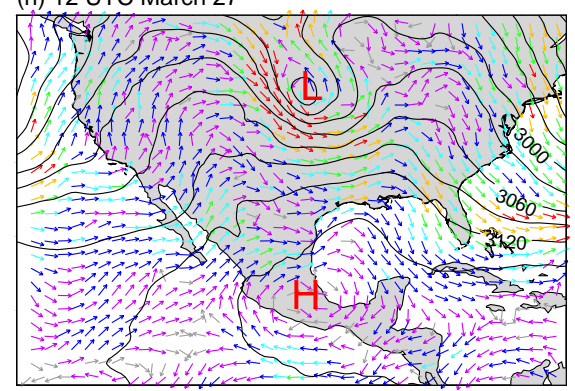

$6-9$

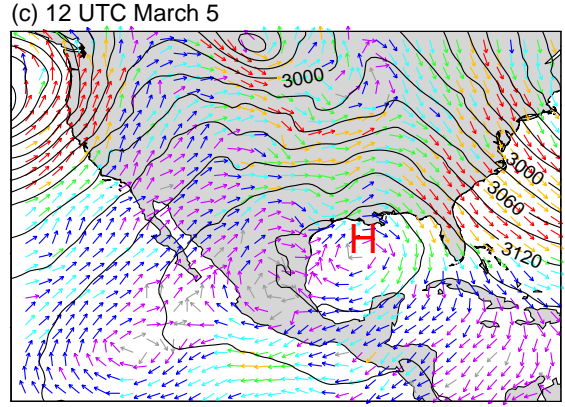

(f) 12 UTC March 11

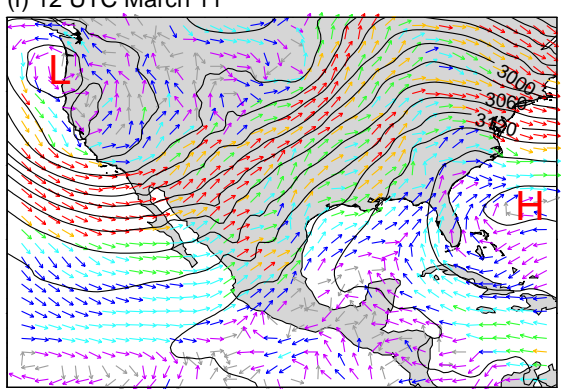

(i) 12 UTC March 17

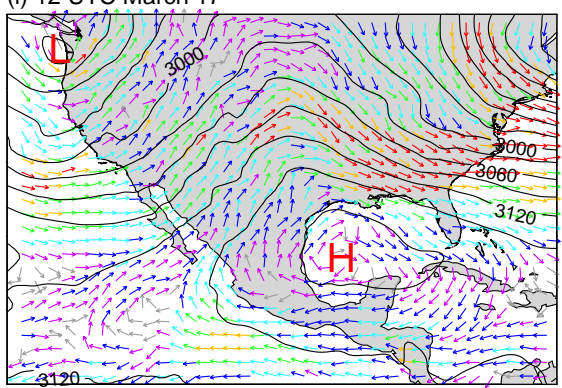

(I) 12 UTC March 23

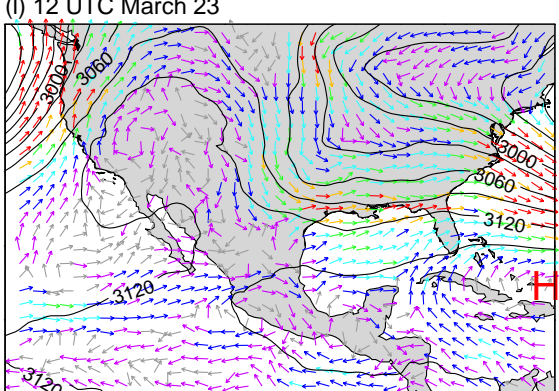

(o) 12 UTC March 29

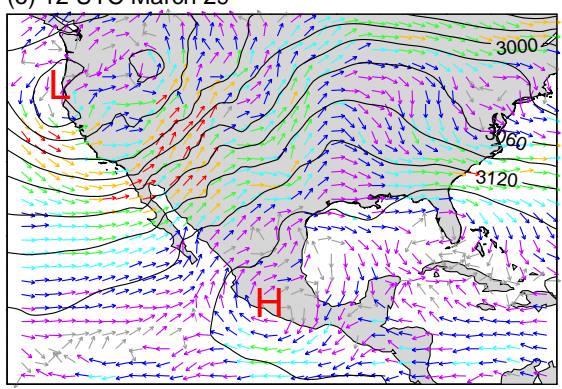

$>18.0 \mathrm{~m} \mathrm{~s}$

Fig. 3. Winds (arrows) and geopotential heights (contours) at $700 \mathrm{hPa}$ at 12:00 UTC for every-other day during the field campaign period during March 2006. Red dot in (a) denotes Mexico City. Contour intervals of $30 \mathrm{~m}$. 

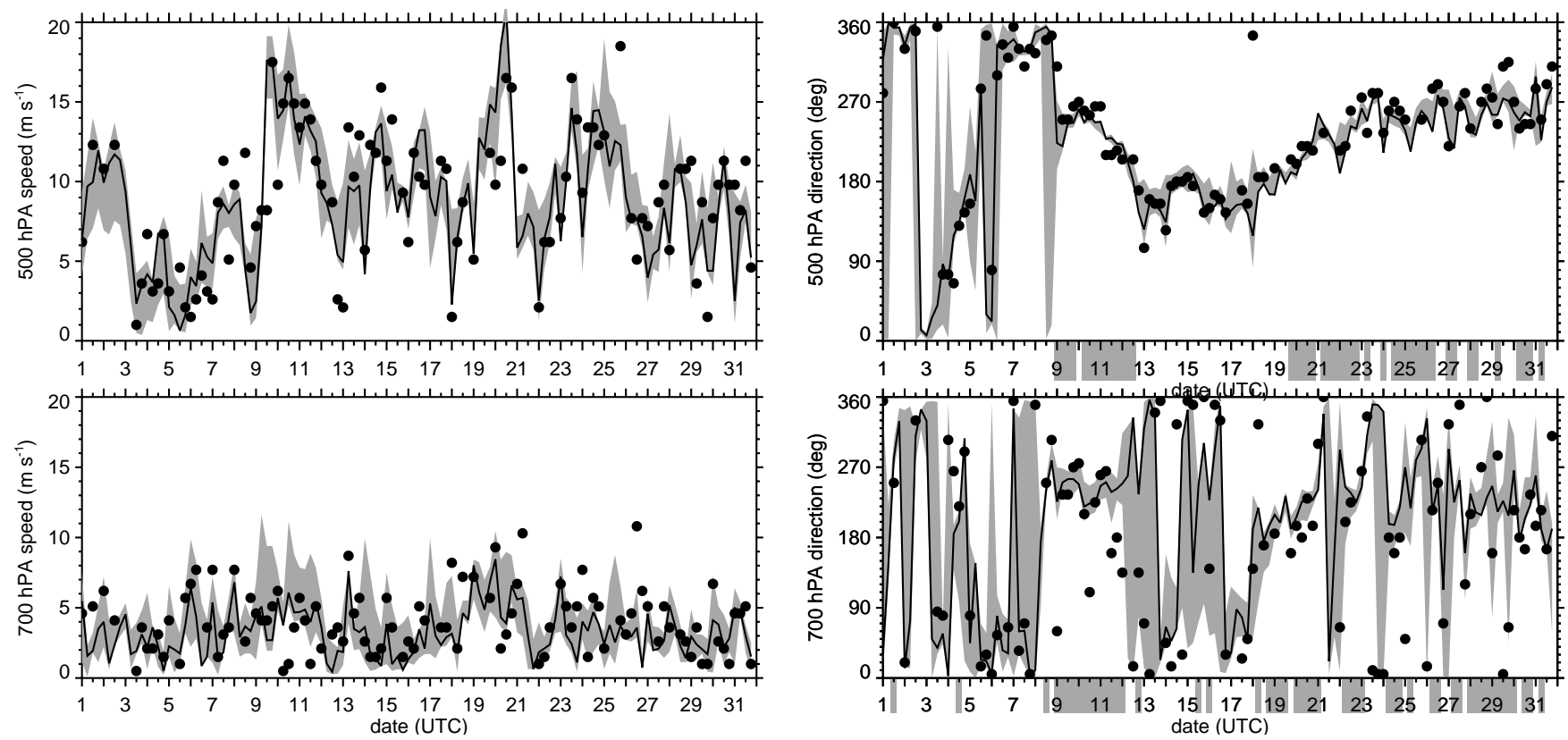

Fig. 4. Wind speed and direction at the 700 (bottom) and $500 \mathrm{hPa}$ (top) levels over Mexico City from the rawinsondes (dots) and GFS analyses closest to Mexico City (line). Gray shading denotes values from the GFS analyses within 0.5 degrees of Mexico City. Gray shading along the x-axis denotes periods with wind directions between 195 and 255 degrees that are favorable for transport from Mexico City to the $\mathrm{T} 1$ and $\mathrm{T} 2$ surface sampling sites.

moved from northwestern Mexico towards the east so that the winds over Mexico City were from the north and east. These synoptic conditions would transport Mexico City pollutants towards the Pacific Ocean. However, the clockwise circulation would eventually transport these pollutants back over Mexico. An upper-level trough propagating through the south-central U.S. on 9 March (Fig. 3e) produced westerly winds over Mexico. The winds became southwesterly between 10 and 12 March (Fig. 3f) as a trough developed over the western U.S. After this trough moved over the northcentral U.S. on 13 March (Fig. 3g), the winds over central Mexico became light and variable. Between 14 and 18 March (Figs. 3h-i) a series of troughs and ridges propagated from west to east across the U.S. that affected the position of the high pressure system over the Gulf of Mexico and lead to variable wind directions over central Mexico. A stronger trough propagated into the south-central U.S., producing stronger southwesterly winds between 19 and 20 March (Fig. 3j). After 21 March (Figs. 3k-o), high pressure gradually developed over southern Mexico that produced westerly winds at this level over central Mexico for the rest of the month.

The time series of wind speed and direction at the 700 and $500 \mathrm{hPa}$ levels for the GFS grid point closest to Mexico City is shown in Fig. 4. The wind directions at $500 \mathrm{hPa}$ were generally northerly or easterly prior to 8 March. After the passage of the upper-level trough on 9 March, the wind direction became southwesterly and then southerly by 12 March.
Wind directions after 13 March gradually became westerly by the end of the month. Wind speeds exceeding $15 \mathrm{~m} \mathrm{~s}^{-1}$ at $500 \mathrm{hPa}$ were associated with the troughs during the 9-11 March and 19-20 March periods. Wind speeds at $700 \mathrm{hPa}$ were almost always less than $10 \mathrm{~m} \mathrm{~s}^{-1}$ and usually less than $5 \mathrm{~m} \mathrm{~s}^{-1}$. Since the winds at $700 \mathrm{hPa}$ are usually within the boundary layer during the day, the directions exhibited more diurnal variation and horizontal variability than at $500 \mathrm{hPa}$.

The shading on the $\mathrm{x}$-axis in Fig. 4 denotes periods of southwesterly wind directions between 195 and 255 degrees that were favorable for transport from Mexico City to the $\mathrm{T} 1$ and $\mathrm{T} 2$ sites. Transport was favorable $\sim 43 \%$ of the time at $700 \mathrm{hPa}$ level and $\sim 36 \%$ of the time at the $500 \mathrm{hPa}$ level during the month assuming the wind remains constant during the 6-h periods when GFS output and rawinsonde data was available. At other times, the T1 and T2 chemistry instrumentation would likely sample either clean air, pollutants from sources other than Mexico City, or aged Mexico City pollutants recirculated around the region.

Also shown in Fig. 4 are the measurements from the Mexico City rawinsondes. While the GFS model wind directions at $500 \mathrm{hPa}$ were very similar to those from the rawinsondes, the wind speeds differed by as much as $5 \mathrm{~m} \mathrm{~s}^{-1}$. Relatively large differences in both speed and direction were evident at the $700-\mathrm{hPa}$ level. Some differences are to be expected since the 0.5-degree grid spacing does not resolve the terrain variations of the Mexican plateau that affect the development of near-surface circulations. In addition, the seven 

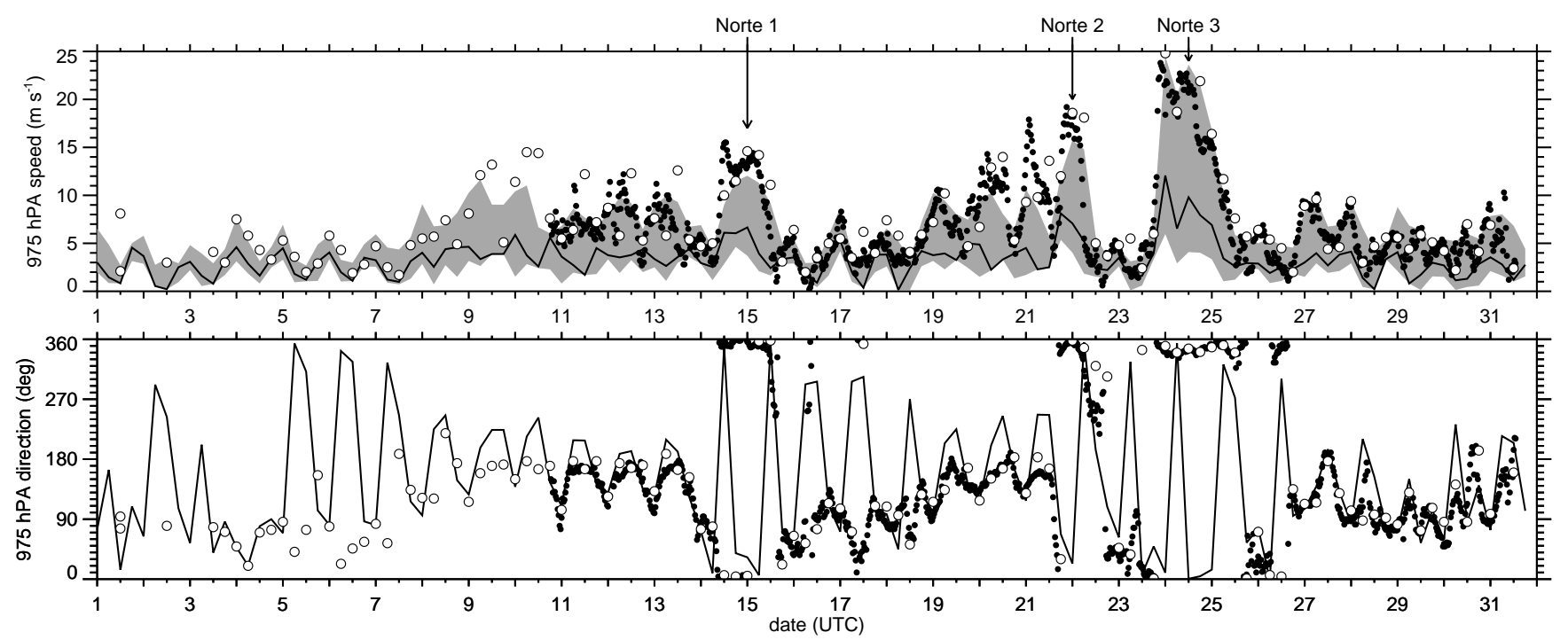

Fig. 5. Wind speed (top) and direction (bottom) at Veracruz during March 2006 from the rawinsondes (white dots), radar wind profiler (black dots), and GFS analysis grid point closet to Veracruz (line). Values from the GFS analyses and radiosondes are from the $975 \mathrm{hPa}$ level and measurements from the radar wind profiler are at $400 \mathrm{~m}$ a.g.l. Gray shading denotes GFS values within one degree of Veracruz.

vertical levels in the GFS analyses below $850 \mathrm{hPa}$ may not fully resolve the vertical variations observed by the rawinsondes. Quality control algorithms may also discard "nonrepresentative" near-surface measurements. It is possible that some of the rawinsondes at 06:00 and 18:00 UTC were not assimilated into the large-scale analyses; however, there was no relationship between the magnitude of the difference and time of day. A similar analysis performed for Veracruz where the terrain is relatively flat also produced relatively large differences between the GFS and rawinsondes both near the surface and aloft (not shown). This suggests a portion of the forecast errors produced by the MILAGRO regional models could be attributed to errors in the synoptic conditions from the GFS analyses.

\section{Cold surge events}

Strong northerly near-surface flows associated with the passage of cold fronts over the Gulf of Mexico occurred three times after 14 March. Although cold fronts gradually dissipate as they propagate into the subtropics, the interaction of the southward moving high-pressure systems with the terrain of the Sierra Madre Oriental often accelerates the northerly flow along the coast. The propagation of strong northerly near-surface flow into the subtropics has been called a " cold surge" (Schultz et al., 1997; Steenburgh et al., 1998), but is commonly known as a "Norte" event in Mexico (Mosino Aleman and Garcia, 1974). Here, we refer to the three cold front passages as Norte 1, Norte 2, and Norte 3. While northerly winds occurred over Mexico City after the passage of the fronts, the wind speeds were much lower than those observed along the coast at lower elevations. In addition to affecting the local transport of pollutants over central Mexico, the Norte events increased humidity, cloudiness, and precipitation that influence the transformation and removal of trace gases and aerosols.

As far as we know, the radar wind profiler at Veracruz provided the first detailed (temporal and vertical resolution) measurements of the Norte events in Mexico. Figure 5 shows the wind speed and direction from the Veracruz radar wind profiler during the field campaign at $400 \mathrm{~m}$ a.g.l., along with the wind speeds and directions from the rawinsonde and GFS analyses at the $975-\mathrm{hPa}$ level that varied between 240 and $420 \mathrm{~m}$ a.g.l. The first Norte event occurred between 14 and 15 March with northerly wind speeds as high as $15 \mathrm{~m} \mathrm{~s}^{-1}$. While the second Norte lasted only several hours on $22 \mathrm{March}$, wind speeds were as high at $20 \mathrm{~m} \mathrm{~s}^{-1}$. The third Norte was the most significant with wind speeds up to $25 \mathrm{~m} \mathrm{~s}^{-1}$. It began on 23 March and strong northerly winds persisted for two days after the frontal passage.

The measurements from the radar wind profiler and rawinsondes were very similar. While the temporal variations in the GFS model winds were qualitatively similar to the measurements, the wind speeds were lower than observed and the wind directions had more diurnal variation than observed. The GFS wind speeds and directions for surrounding grid points over the ocean were closer to the measurements, suggesting that the differences resulted primarily from issues associated with resolving the coast.

The vertical wind profiles in speed and direction from the Veracruz radar wind profiler during the second and third Norte events are shown in Fig. 6. The potential temperature contours in this figure were obtained by temporal linear 

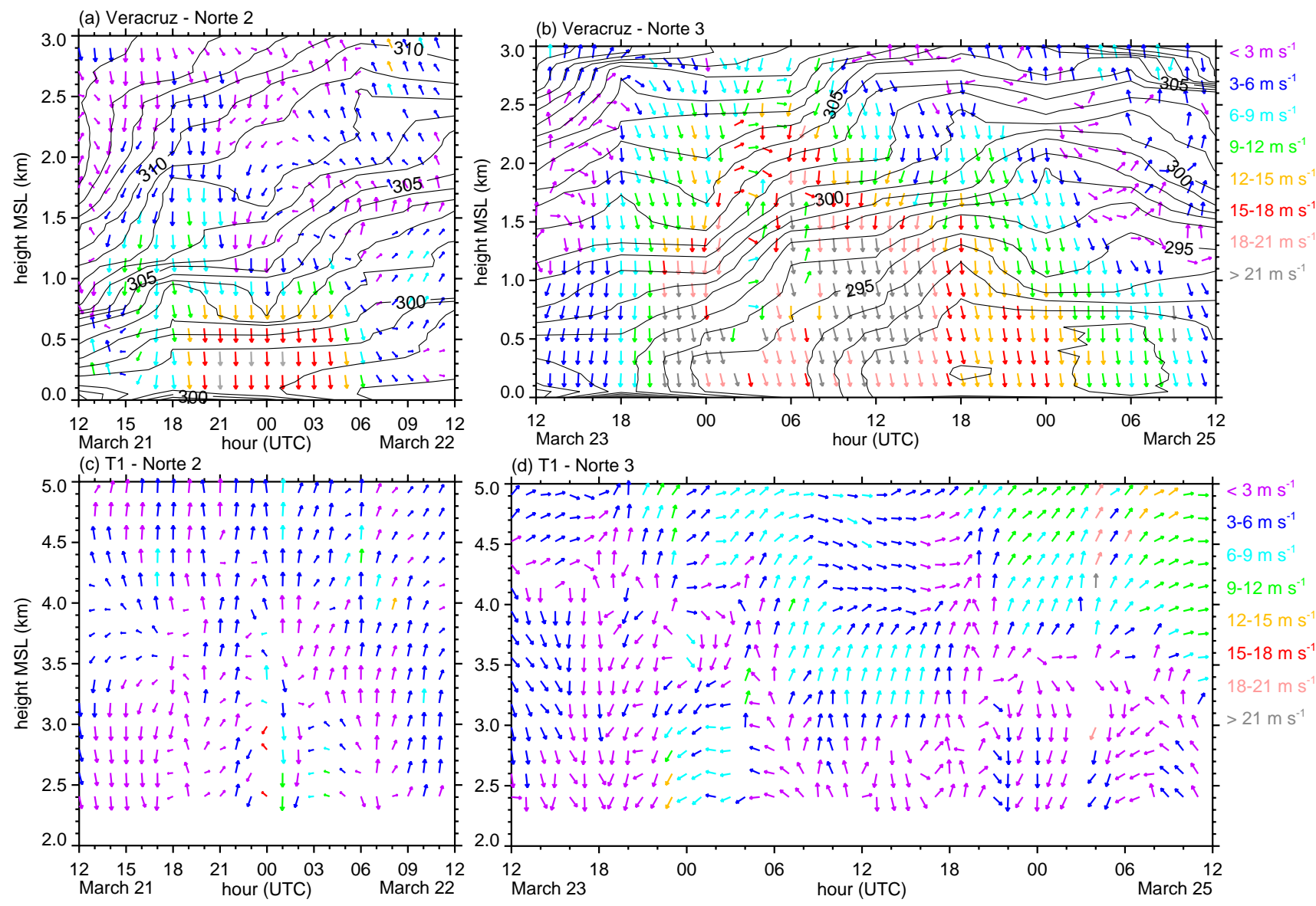

Fig. 6. Wind profiles from the Veracruz (a and $\mathbf{b})$ and $\mathrm{T} 1$ ( $\mathbf{c}$ and $\mathbf{d}$ ) radar wind profilers during the second and third Norte. Black contours denote potential temperature contours obtained by interpolating in time the Veracruz soundings available at 6-h intervals.

(a) 12 UTC March 23

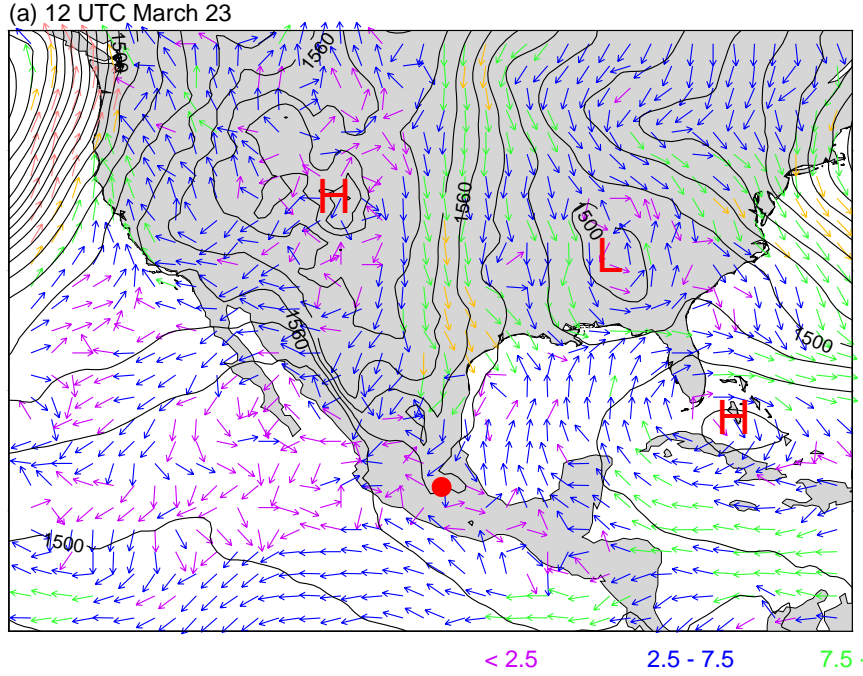

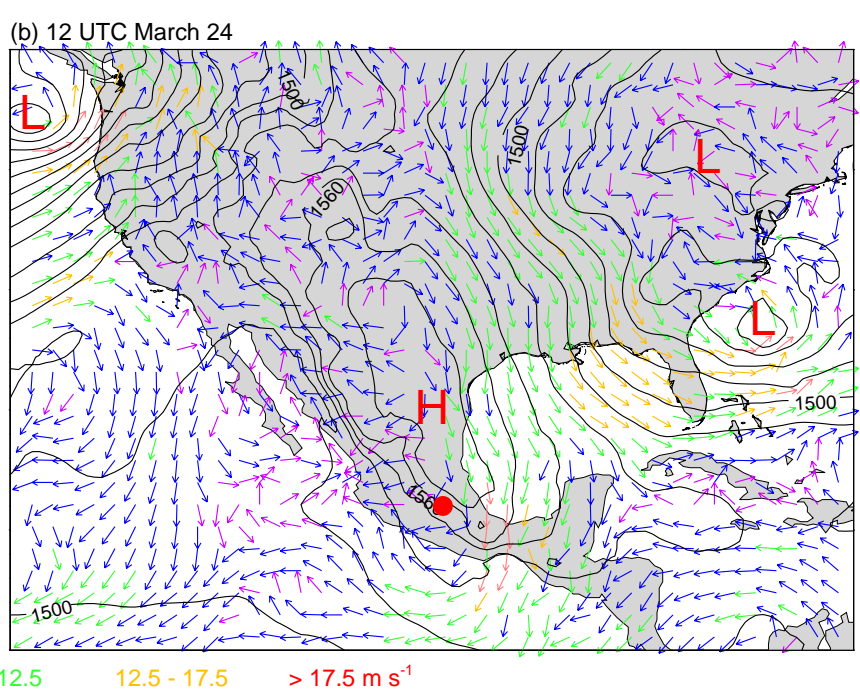

Fig. 7. $850 \mathrm{hPa}$ geopotential heights (contours) and winds (arrows) during the third Norte at (a) 12:00 UTC 23 March and (b) 12:00 UTC 24 March. 

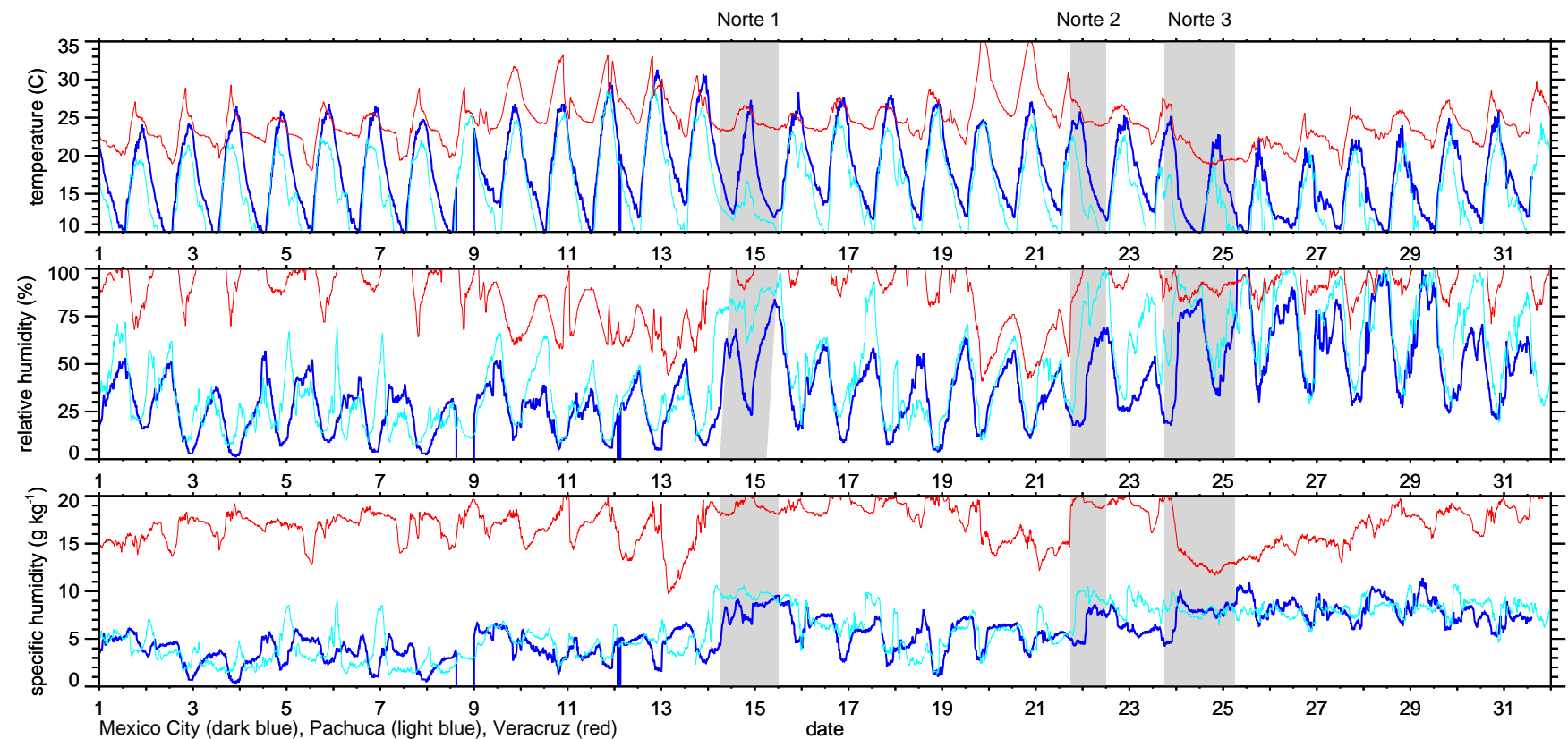

Fig. 8. Temperature (top), relative humidity (middle), and specific humidity (bottom) at Veracruz (gray), Pachuca (thin black) and Mexico City (thick black) during the field campaign. Dark shading denotes periods influenced by Norte events at Veracruz.

interpolation of the rawinsonde temperature profiles collected every six hours. During the second Norte (Fig. 6a), wind speeds greater than $12 \mathrm{~m} \mathrm{~s}^{-1}$ occurred within $0.6 \mathrm{~km}$ of ground between 19:00 UTC 21 March and 05:00 UTC 22 March. Mechanical mixing associated with the strongest winds contributed to the near-neutral layer within $0.4 \mathrm{~km}$ of the ground. The third Norte event (Fig. 6b) had stronger wind speeds over a much greater depth. Wind speeds exceeding $12 \mathrm{~m} \mathrm{~s}^{-1}$ extended up to $2.5 \mathrm{~km}$ m.s.l. a few hours after the passage of the front. Despite the high wind speeds, mechanical mixing produced a neutral layer only in the lowest few hundred meters. Wind speeds gradually diminish after 12:00 UTC 25 March, but remain northerly until 19:00 UTC 26 March. Northerly flows at T1 for the second (Fig. 6c) and third (Fig. 6d) Norte were much weaker and of shorter duration.

The winds and geopotenial heights at the $850 \mathrm{hPa}$ level at two times are shown in Fig. 7 to illustrate the synoptic conditions just prior to the arrival of the front at Veracruz at 12:00 UTC 23 March and during the third Norte at 12:00 UTC 24 March. At 12:00 UTC 23 March (Fig. 7a), northerly winds between 10 and $17.5 \mathrm{~m} \mathrm{~s}^{-1}$ occurred over the Great Plains from northern Canada into northern Mexico as a result of a strong pressure gradient across the central U.S. Surface temperatures dropped below $0^{\circ} \mathrm{C}$ as far south as Texas. After the front moved past Veracruz (Fig. 7b) strong northerly and northwesterly winds were present over the entire Gulf of Mexico. The winds accelerated to greater than $20 \mathrm{~m} \mathrm{~s}^{-1}$ through the terrain gap in the southern isthmus of Mexico and over the Gulf of Tehuantepec. The synoptic con- ditions, gap winds, and cloud distribution for this Norte were very similar to the cold surge of 12-14 March 1993 described by Steenburgh et al. (1998).

The effects of the three Norte events on the 2-m temperature, relative humidity, and specific humidity at Veracruz, Pachuca, and Mexico City are shown in Fig. 8. Temperatures over the coast were higher and have less diurnal range than temperatures over the plateau, as expected. Daily maximum temperatures during each Norte drop a few degrees from the preceding days. During the first thirteen days of the field campaign the atmospheric moisture was very low over the plateau with relative humidities usually less than $50 \%$ and mixing ratios less than $7 \mathrm{~g} \mathrm{~kg}^{-1}$. Afternoon relative humidity and specific humidity often dropped to less $10 \%$ and $3 \mathrm{~g} \mathrm{~kg}^{-1}$, respectively. During the first Norte, relative humidity rose as the temperatures decreased and specific humidity increased to $8-10 \mathrm{~g} \mathrm{~kg}^{-1}$. Since there are no significant local sources of moisture over the plateau, the increase of moisture must have been associated with transport from the Gulf of Mexico. While the humidity dropped somewhat after the first Norte, the relative and specific humidities were higher on average than during the dry period earlier in the month. Humidities over the plateau increased again during the second and third Norte events. Specific humidity was usually between 7 to $10 \mathrm{~g} \mathrm{~kg}^{-1}$ after the third Norte until the end of the month.

The transport of moisture from the Gulf of Mexico towards Mexico City for the second Norte is depicted in Fig. 9. A sharp increase in specific humidity was observed at Pachuca (Fig. 9a) between 20:00 and 21:00 UTC on 21 


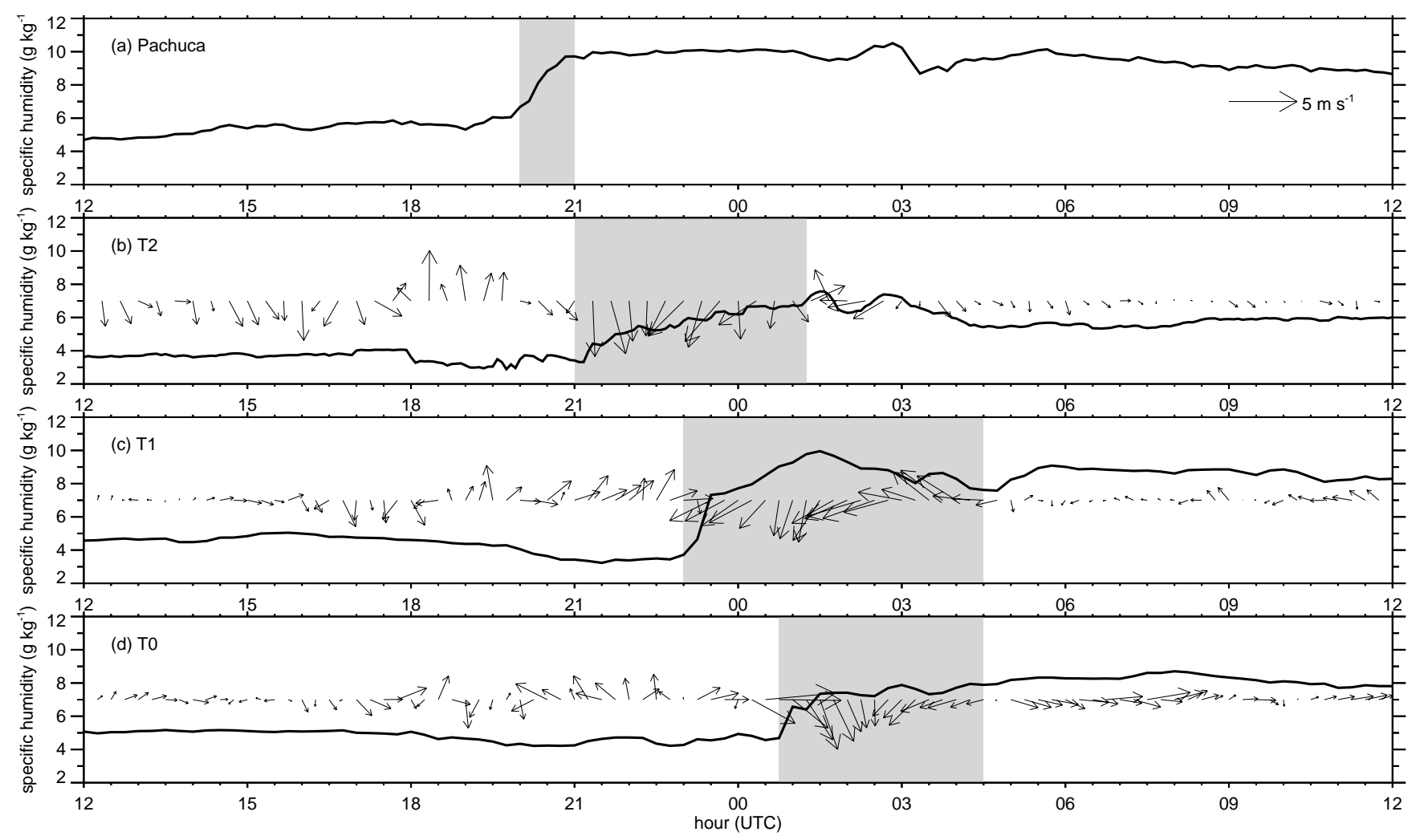

Fig. 9. Specific humidity and winds observed at (a) Pachuca, (b), T2, (c) T1, and (d) T0 between 12:00 UTC March 21 and 12:00 UTC 22 March. Shading denotes rise in humidity and shift to northerly winds associated with the start of the second Norte. Wind speeds at Pachuca were missing at this time.

March. Unfortunately, the wind measurements at Pachuca were missing for most of March. An increase in specific humidity was observed at T2 one hour later at 21:00 UTC and northerly winds were associated with the gradual increase in specific humidity over the next $3.5 \mathrm{~h}$. The Norte arrived at T1 and T0 around 23:00 UTC 21 March and 00:30 UTC 22 March, respectively. The operational meteorological sites in Mexico City (Fig. 2b) indicated that the northerly flow propagated to the southern end of the basin by 03:00 UTC (not shown). After the passage of the Norte, specific humidity at T0 was $1-2 \mathrm{~g} \mathrm{~kg}^{-1}$ lower than at Pachuca, suggesting that mixing processes diluted the air mass as it was transported over the plateau. These measurements indicate that the northerly winds propagated over central plateau from Pachuca to Mexico City in about $4.5 \mathrm{~h}$ at an average speed of about $4.9 \mathrm{~m} \mathrm{~s}^{-1}$. The propagation of moisture over the plateau for the first and third Nortes was similar to Fig. 9 (not shown).

The strong winds associated with the cold surges contributed to periods of wind-blown dust over the central plateau in addition to convective outflow and interactions of local and regional thermally-driven circulations. Measurements of PM10 exceeded $300 \mu \mathrm{g} \mathrm{m}^{-3}$ at a number of operational stations in Mexico City on 8, 9, 10, 13, 14, 16, 17,
18, 19, 20, 21, and 23 March. The highest $\mathrm{PM}_{10}$ values usually occurred when near-surface wind speeds increased significantly over the eastern side of the valley where the dry and sparsely vegetated soil is susceptible to wind erosion. Because of the proximity of urban areas and dust emission sources, the evolution of particulates downwind of Mexico City was likely influenced by the interaction of mineral dust and anthropogenic trace gases.

\section{Clouds and precipitation}

Not surprisingly, the passage of cold fronts and the increase in moisture led to increased cloudiness in the region. This is an important factor during MILAGRO because the scattering and absorption of radiation by clouds reduces the photochemical production below cloud base and increases photochemical production above cloud tops, vertical transport within clouds alters the distribution of pollutants, and precipitation removes trace gases and particulates from the atmosphere. Table 2 qualitatively summarizes the daytime cloud conditions during the field campaign based on inspection of visible satellite images while Fig. 10 quantifies the cloudiness at $\mathrm{T} 1$ and $\mathrm{T} 2$ by using fractional cloudiness, $\mathrm{F}_{c}$, derived from multi-band rotating shadowband radiometer (MFRSR) 

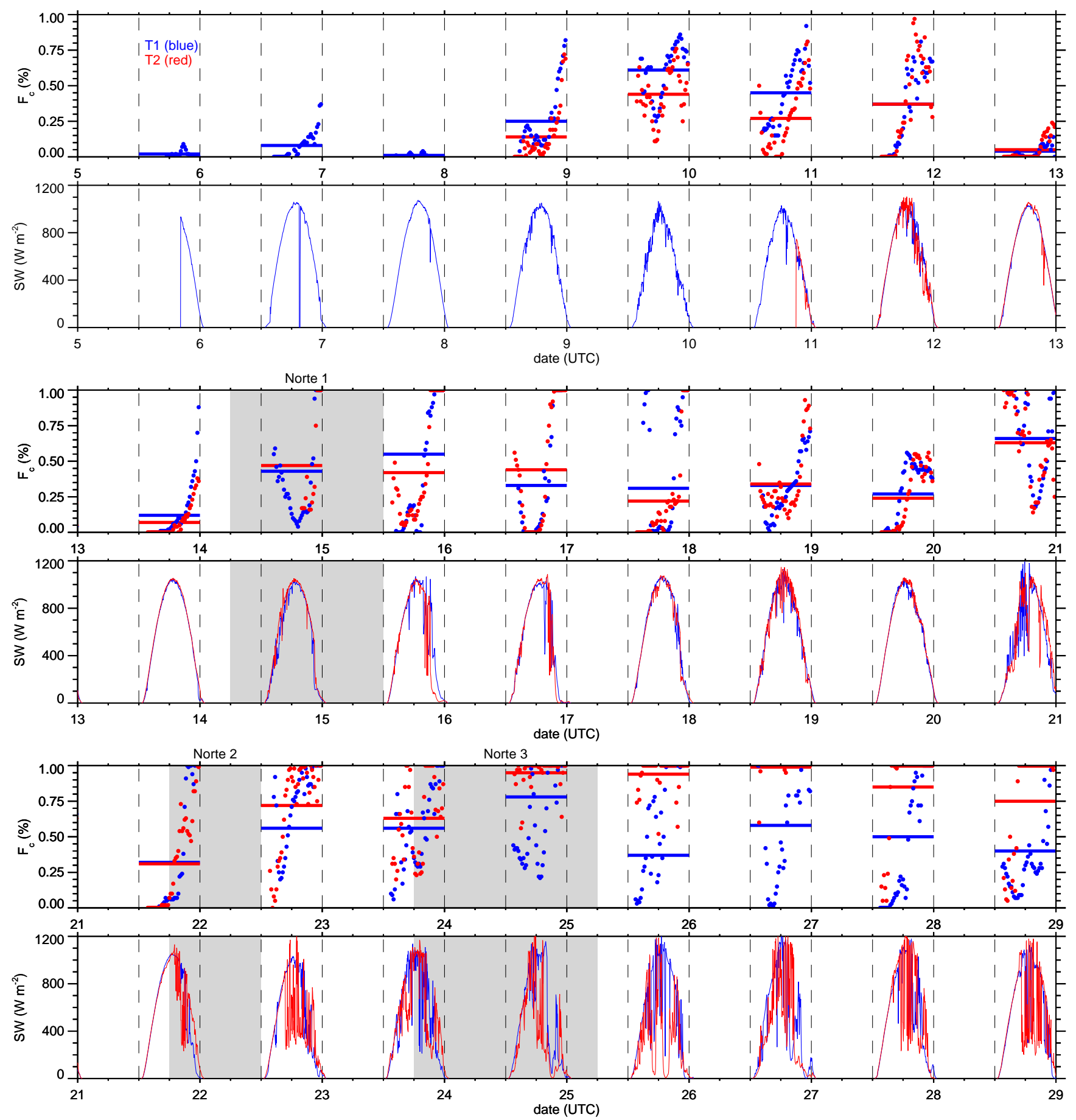

Fig. 10. Fractional cloudiness, $F_{c}$, and total downward shortwave radiation, $S W$, during the field campaign period at the $T 1$ (blue) and $T 2$ (red) site. Dots denote 15-min averages and thick horizontal lines denote afternoon averages of the fractional cloudiness. Shading denotes Norte periods and dashed lines denote sunrise and sunset.

measurements (Long et al., 2006) and total downward shortwave radiation, SW, from Eppley broadband radiometers. The variations in cloudiness and shortwave radiation at other nearby sites in Mexico City and Pachuca were similar to those shown in Fig. 10.
The high daily average shortwave radiation at $\mathrm{T} 1$ and $\mathrm{T} 2$ and other operational measurements indicates mostly sunny skies occurred over the central plateau between 1 and 13 March. Somewhat lower daily averages at stations located just east of the Sierra Madre Oriental (not shown) between 3 
Table 2. Cloudiness during MILAGRO.

\begin{tabular}{|c|c|c|c|c|c|c|}
\hline March & T0-T1-T2 morning & T0-T1-T2 afternoon & $\begin{array}{l}\text { Mountains in the } \\
\text { vicinity of Mex- } \\
\text { ico City }\end{array}$ & Deep convection & Sierra Madre Oriental foothills & Cirrus \\
\hline 1 & CLR & CLR & $\mathrm{PC}$ & ISO & $\mathrm{PC}$ & No \\
\hline 2 & CLR & CLR & CLR & none & SCA & No \\
\hline 3 & CLR & CLR & CLR & none & $\mathrm{PC}$ & No \\
\hline 4 & CLR & CLR & CLR & none & $\mathrm{PC}$ & No \\
\hline 5 & CLR & CLR & CLR & none & $\mathrm{MC}$ & No \\
\hline 6 & CLR & CLR & CLR & none & $\mathrm{PC}$ & No \\
\hline 7 & CLR & CLR & CLR & none & SCA & No \\
\hline 8 & CLR & CLR & $\mathrm{PC}$ & none & CLR & Yes \\
\hline 9 & CLR & CLR & CLR & none & CLR & Yes \\
\hline 10 & CLR & CLR & CLR & none & CLR & Yes \\
\hline 11 & CLR & CLR & CLR & none & CLR & Yes \\
\hline 12 & CLR & CLR & $\mathrm{PC}$ & none & CLR & Yes \\
\hline 13 & CLR & CLR & $\mathrm{PC}$ & ISO & CLR & No \\
\hline 14 & CLR & $\mathrm{PC}$ & $\mathrm{PC}$ & ISO & $\mathrm{MC}$ & No \\
\hline 15 & CLR & MC & $\mathrm{PC}$ & SCA & $\mathrm{PC}$ & No \\
\hline 16 & CLR & $\mathrm{MC}$ & $\mathrm{PC}$ & SCA & $\mathrm{PC}$ & No \\
\hline 17 & CLR & $\mathrm{PC}$ & $\mathrm{PC}$ & ISO & $\mathrm{PC}$ & Yes \\
\hline 18 & CLR & CLR & $\mathrm{PC}$ & none & $\mathrm{PC}$ & Yes \\
\hline 19 & CLR & CLR & $\mathrm{PC}$ & none & SCA & No \\
\hline 20 & CLR & CLR & CLR & none & CLR & Yes \\
\hline 21 & CLR & $\mathrm{PC}$ & $\mathrm{PC}$ & none & $\mathrm{PC}$ & Yes \\
\hline 22 & CLR & $\mathrm{PC}$ & $\mathrm{PC}$ & none & $\mathrm{PC}$ & No \\
\hline 23 & CLR & $\mathrm{PC}$ & $\mathrm{PC}$ & ISO & $\mathrm{MC}$ & No \\
\hline 24 & CLR & $\mathrm{PC}$ & $\mathrm{PC}$ & ISO & MC & No \\
\hline 25 & PC & $\mathrm{PC}$ & $\mathrm{PC}$ & none & $\mathrm{PC}$ & No \\
\hline 26 & CLR & $\mathrm{PC}$ & $\mathrm{PC}$ & ISO & $\mathrm{PC}$ & No \\
\hline 27 & CLR & $\mathrm{PC}$ & $\mathrm{PC}$ & ISO & $\mathrm{PC}$ & No \\
\hline 28 & CLR & $\mathrm{PC}$ & $\mathrm{PC}$ & ISO & $\mathrm{PC}$ & No \\
\hline 29 & CLR & $\mathrm{PC}$ & $\mathrm{PC}$ & ISO & $\mathrm{PC}$ & No \\
\hline 30 & CLR & $\mathrm{PC}$ & $\mathrm{PC}$ & ISO & $\mathrm{PC}$ & No \\
\hline 31 & CLR & $\mathrm{PC}$ & $\mathrm{PC}$ & ISO & SCA & No \\
\hline
\end{tabular}

$\mathrm{CLR}=$ clear

SCA $=$ scattered

$\mathrm{PC}=$ partly cloudy

$\mathrm{MC}=$ mostly cloudy

ISO $=$ isolated

and 5 March were associated with marine stratus that formed along the eastern slopes of the plateau as a result of the northeasterly winds aloft (Figs. 3 and 4). Afternoon averaged $\mathrm{F}_{c}$ was as large as $60 \%$ over the plateau between 9 and 13 March as a result of cirrus clouds transported into the region by upper-level southwesterly flow, but the cirrus clouds lead to only small reductions in downward solar radiation. Increases in low-level clouds occurred during the first Norte on 14 March at all sites. After the Norte, mostly clear skies were usually observed over central Mexico during the morning, but the increased humidity provided favorable conditions for afternoon partly cloudy conditions to develop over the mountain ranges and the plateau on several days between 15 and
21 March. $F_{c}$ at $\mathrm{T} 1$ and $\mathrm{T} 2$ was quite similar during this period. While clear skies were usually observed during the morning in the vicinity of Mexico City for the remainder of the month, the second and third Norte events led to periods of mostly cloudy conditions along the coast and increases in afternoon cloudiness over the plateau. After the third Norte, the increased humidity and synoptic conditions were favorable for continued afternoon partly cloudy conditions in the region and $\mathrm{F}_{c}$ at $\mathrm{T} 2$ became significantly larger than at $\mathrm{T} 1$. Two factors likely contributed to the higher cloudiness at $\mathrm{T} 2$ : the location of the site closer to regions of orographic uplift and decreased atmospheric static stability, as will be shown later. 
(a) Terra Satellite: 1630 UTC March 21

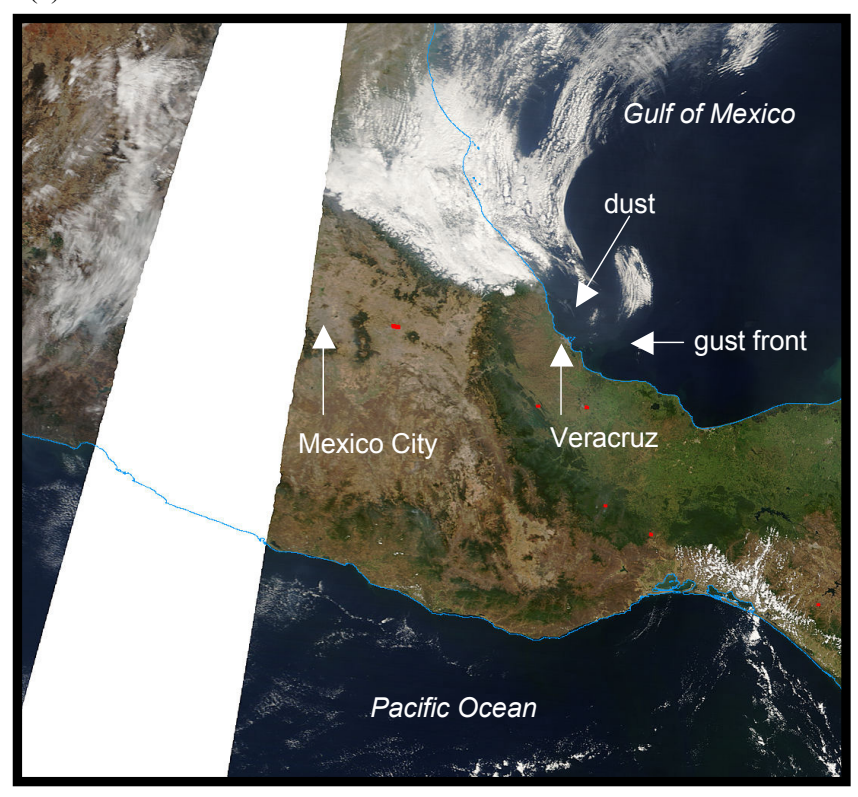

(b) Aqua Satellite: 1930 UTC March 24

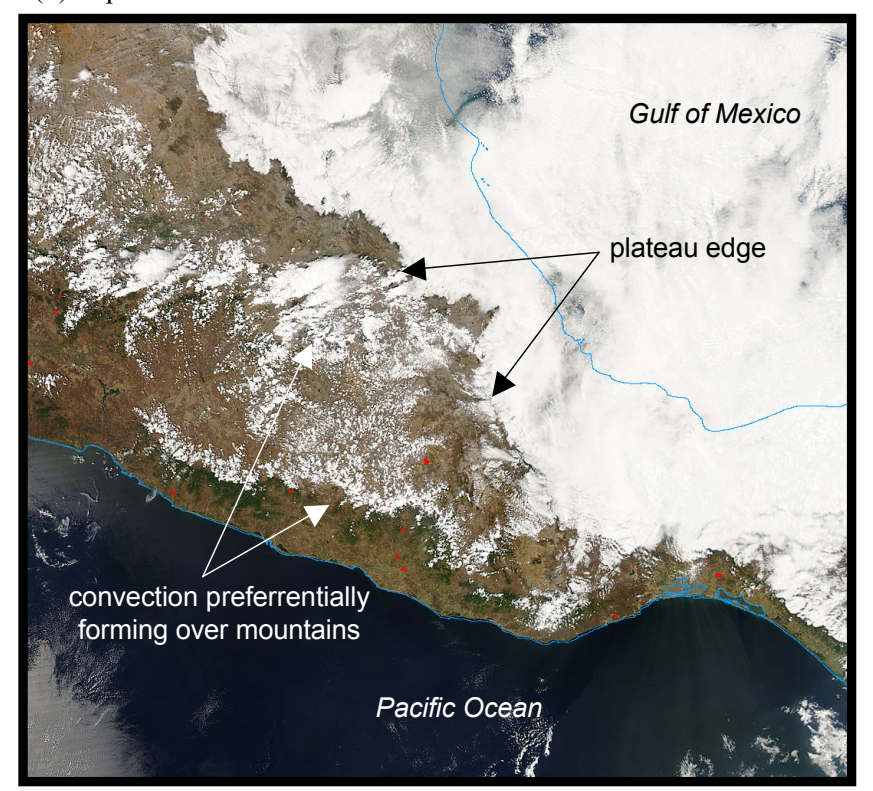

Fig. 11. MODIS satellite image during the (a) second and (b) third Norte.

MODIS visible satellite images at $\sim 16: 30$ UTC on 21 March and 20:10 UTC 24 March are shown in Fig. 11 to illustrate the spatial distribution of cloudiness over central Mexico during the second and third Norte. At 16:30 UTC on $21 \mathrm{March}$, the strong near-surface northerly winds began to increase at Veracruz and produced blowing dust along the coast (Fig. 11a). Partly to mostly cloudy conditions occurred behind the front over the Gulf of Mexico and the coastal plain, while mostly sunny conditions were observed over the rest of Mexico. More widespread cloudiness was associated with the stronger third Norte. Mostly cloudy conditions were produced over the Gulf of Mexico, with the western boundary along the Sierra Madre Oriental at approximately $2 \mathrm{~km}$ m.s.l. (Fig. 11b). The increased moisture produced partly cloudy conditions over the plateau, primarily over mountain ranges.

The increases in humidity and the morning clear-sky insolation over the plateau after 14 March were favorable for thermally-driven slope flows so that shallow and deep convective clouds developed preferentially over the highest terrain during the afternoon. Satellite images indicated that deep convection occurred over the central plateau during the afternoons of 13-17 March, 23-24 March and 25-31 March. The stability of the atmosphere also decreased during these periods as shown in Fig. 12a by the $\mathrm{K}$ index derived from the rawinsondes at Mexico City. The $\mathrm{K}$ index is a simple index derived from vertical temperature and moisture gradients below $500 \mathrm{hPa}$ (George, 1960). In general, higher values of $\mathrm{K}$ indicate an increased probability of air mass thunderstorms. Values greater than 28 have been used to indicate a $50 \%$ or greater probability, but various studies have found different specific probabilities using the $\mathrm{K}$ index. This index also does not account for convergence resulting from the topographic variations and thermally-driven circulations over the plateau that would enhance convective instability in certain regions. The $\mathrm{K}$ index is low during the first part of the field campaign between 2 and 13 March when clear skies were usually observed. Increases in the $\mathrm{K}$ index and precipitable water (Fig. 12b) were associated with each of the Norte events. The $\mathrm{K}$ index remained high after the third Norte, indicating that conditions over the plateau were favorable for convective activity.

The increased cloudiness was also accompanied by scattered precipitation, as shown by the precipitation within the Mexico basin and at Pachuca in Fig. 12c, and the accumulated precipitation prior to and after the second Norte, as shown in Fig. 13. Light rain was observed in Mexico City and at Pachuca after the second Norte (Fig. 12c). The precipitation usually occurred during the late afternoon within a few hours after sunset. Although precipitation was not observed between 13 and 17 March, scattered convection in the region produced rainfall at other locations. Hail and lightning were observed in the vicinity of T1 on 16 March.

As shown in Fig. 13, precipitation before 21 March was light with only five stations in central Mexico reporting rainfall exceeding $3 \mathrm{~mm}$ (Fig. 13a). Most of this precipitation was associated with isolated deep convective activity after the first Norte on 14 March (Table 2). After 22 March, precipitation was observed at most stations in central Mexico (Fig. 13b). The increased frequency of convective activity associated with the third Norte led to precipitation exceeding $18 \mathrm{~mm}$ at five stations. The increased cloudiness and 
(a)

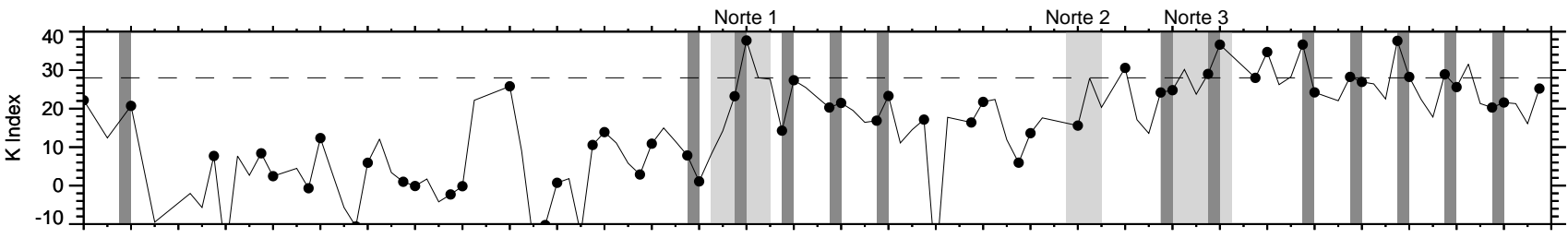

(b)

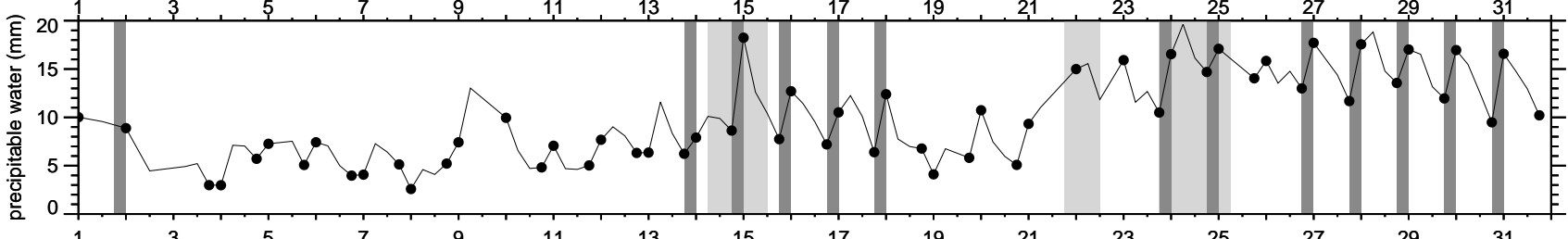

(c)

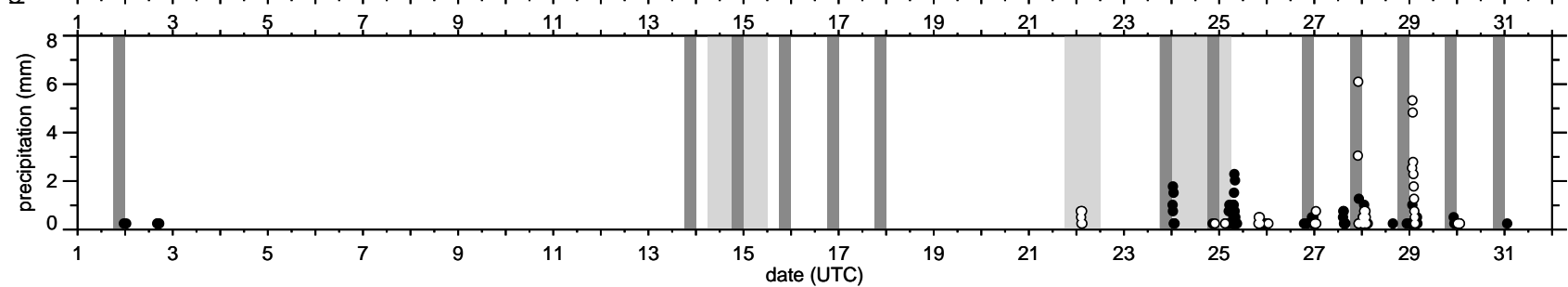

Fig. 12. (a) $\mathrm{K}$ index and (b) precipitable water from the Mexico City soundings and (c) precipitation from stations in the vicinity of Mexico City (black dots) and at Pachuca (white dots). Dots in (a) and (b) are for the 18:00 and 00:00 UTC soundings to highlight afternoon periods. Light gray denotes Norte events and dark gray denotes afternoons when convective activity occurred over the central plateau.
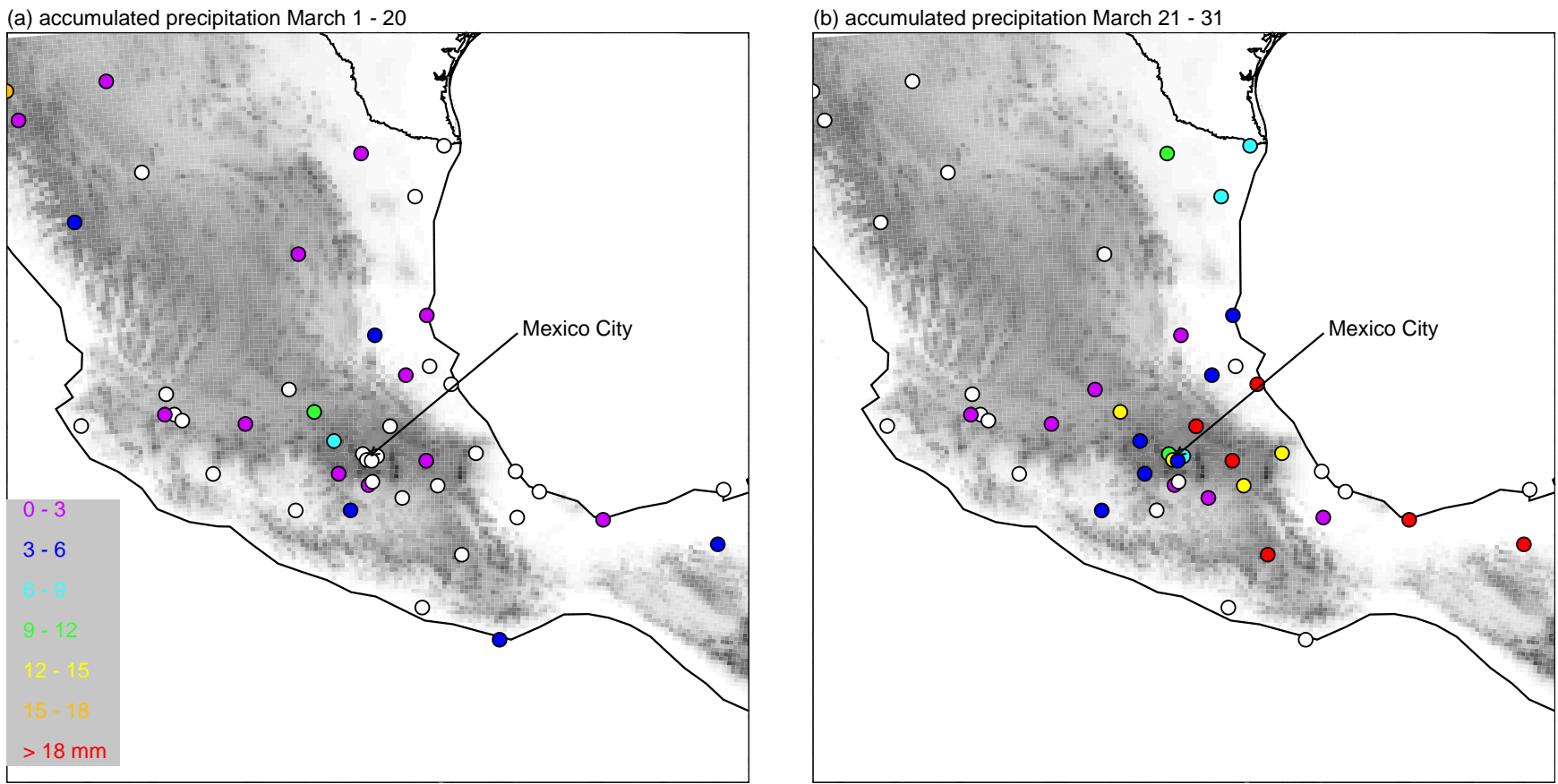

Fig. 13. Accumulated precipitation over Mexico between (a) 1 and 21 March and (b) 22 and 31 March corresponding to periods before and after Norte event 1.

precipitation during the later part of the month also increases the possibility of the pollutants being diluted by convective transport and wet scavenging downwind of Mexico City.

\section{Biomass burning}

The month of March was also chosen as the MILAGRO experimental period because the number of fires is normally 
(a) fires between March 1 and 20

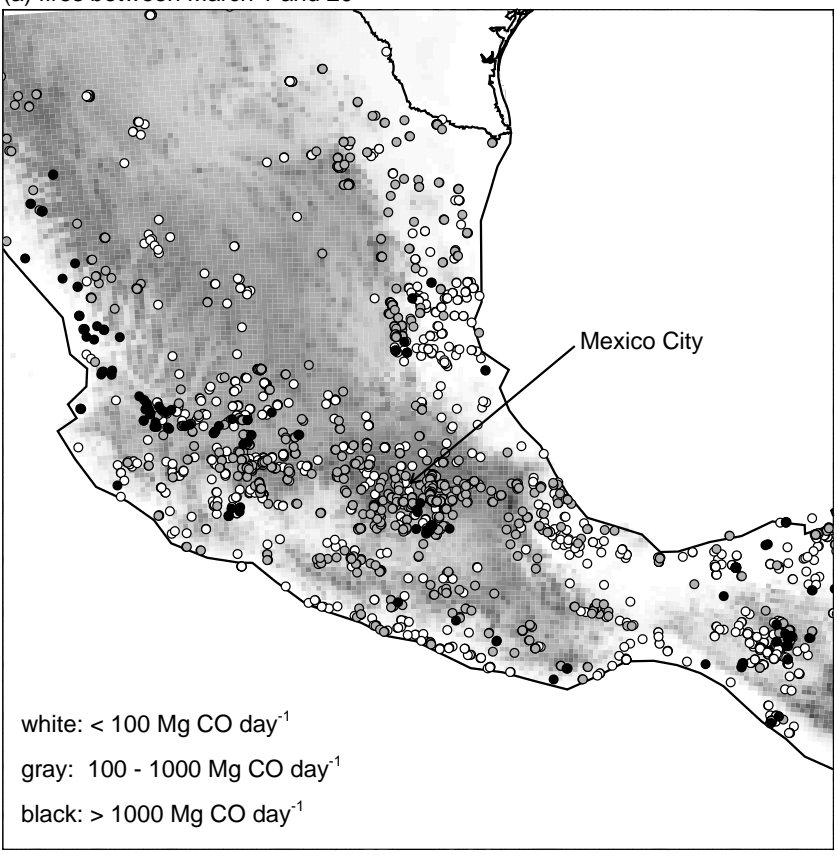

(b) fires between March 21 and 31

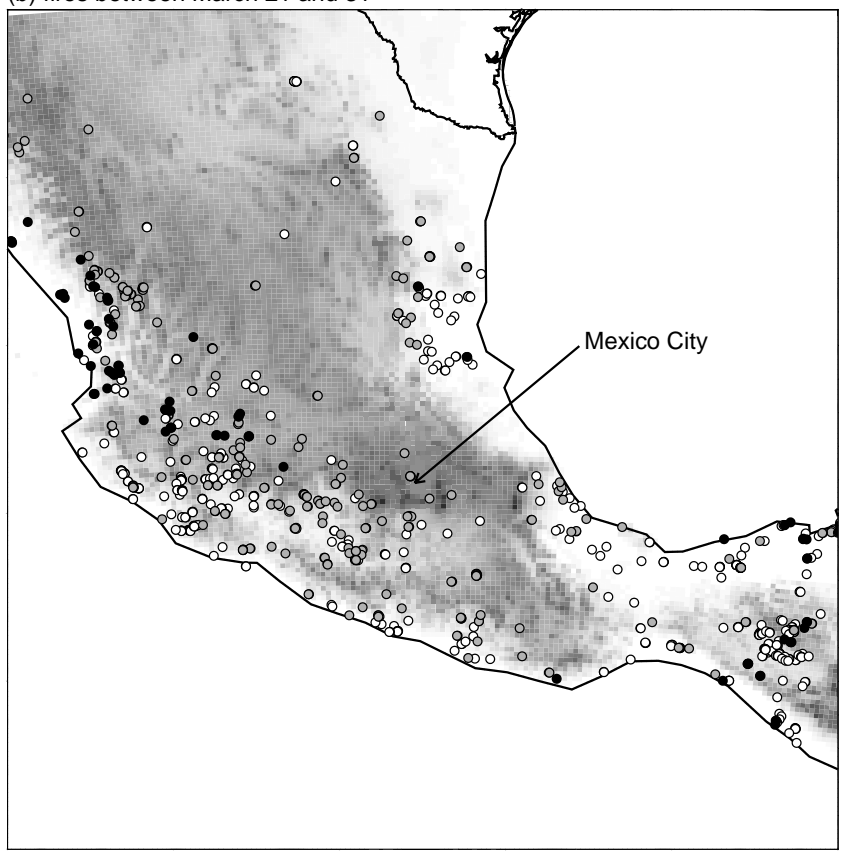

Fig. 14. Fires before and after Norte event 2 as derived from MODIS satellite images as described by Wiedinmyer et al. (2006).

relatively low during this month. Most planned and unplanned biomass burning in Mexico occurs between March and June, with the peak number of fires occurring during May (Wiedinmyer et al., 2006). In this way, scientists could focus on the evolution of the Mexico City pollutants without the complications of trace gases and aerosols from fire sources mixing with and altering the evolution of the Mexico City plume. Smoke would also alter atmospheric chemistry and contribute to the aerosol optical depth in the vicinity of Mexico City. However, a number of fires that likely contributed to poorer air quality and visibility occurred in central Mexico during March 2006, as reported by scientists on the research aircraft and by satellite images.

Daily estimates of trace gas and particulate emissions from fires were made using the MODIS thermal anomalies product and land cover information as described by Wiedinmyer et al. (2006). Terra and Aqua satellites pass over or near Mexico twice a day so that this methodology can miss short-lived fires. Many fires observed, for example by the USFS aircraft, were small shrub and agricultural clearing fires that were not detected by satellite. Carbon monoxide emissions from fires before and after 21 March are shown in Fig. 14. Prior to the second Norte during dry conditions with clear skies, numerous fires were observed throughout Mexico (Fig. 14a). Many of these fires occurred in the vicinity of Mexico City with emissions of carbon monoxide from several estimated to exceed $1000 \mathrm{Mg}_{\text {day }^{-1}}{ }^{-}$. MODIS satellite images showed that many of these smoke plumes were close to Mexico City. Not surprisingly, the increased cloudiness and precipitation over central Mexico (Figs. 10 and 13) led to fewer fires with significantly lower emissions after the second Norte (Fig. 14b).

The number of fires in Fig. 14b may be underestimated since the clouds would also obscure fires from the satellite measurements. Nevertheless, the results show that there was a greater probability of interactions between the Mexico City plume and biomass burning smoke plumes during the first three weeks of MILAGRO. The relative contribution of anthropogenic and biomass burning sources to the aerosol optical properties will be determined by future measurement and modeling studies of atmospheric chemistry.

\section{Regional-scale boundary layer structure and winds}

Whiteman et al. (2000) quantified the average horizontal temperature and humidity gradients between the central plateau and the surrounding free atmosphere by employing the radiosonde measurements obtained from Mexico City and the coastal regions surrounding the plateau at 12:00 and 00:00 UTC during March 1997. A similar analysis of the mean profiles during MILAGRO is shown in Fig. 15, except that the four-times per day soundings permit average profiles at 06:00 and 18:00 UTC to be included in the diurnal variations. At 18:00 UTC, the growing convective boundary layer (CBL) over Mexico City produced near-surface temperatures that were warmer than the surrounding free atmosphere. By 00:00 UTC, the average mixed layer height was $\sim 5 \mathrm{~km}$ m.s.l. ( $\sim 2.6 \mathrm{~km}$ a.g.1.). Potential temperatures east and south of the Mexican plateau at Veracruz and Acapulco, 

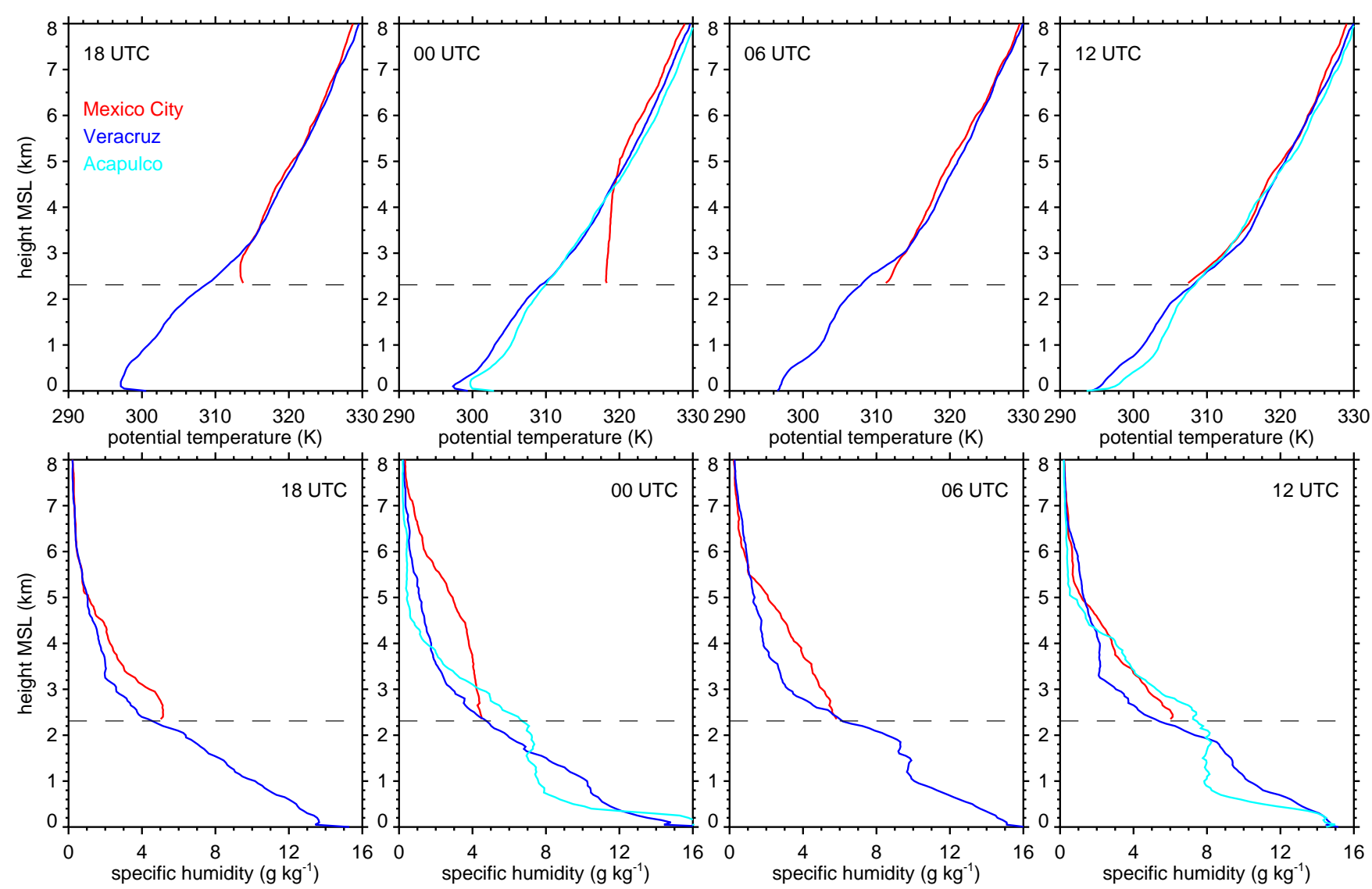

Fig. 15. Average potential temperature and specific humidity profiles at 6-h intervals from the Mexico City, Veracruz, and Acapulco rawinsondes during the field campaign. The dashed line denotes the elevation of the Mexico City basin.

respectively, were almost identical. The CBL over the basin produces regional horizontal temperature gradients that drive the regional-scale circulations. Smaller-scale heating and terrain geometry associated with the mountain ranges leads to local-scale circulations. The specific humidity profiles in Fig. 15 show an increase in moisture above the plateau during the daytime. Since there are no significant moisture sources on the plateau itself and the growing CBL would entrain drier air into the mixed layer, the profiles suggest that advection from the surrounding coastal regions was responsible for this moistening.

After sunset, the CBL collapsed so that by morning (around 12:00 UTC) the potential temperatures at Mexico City were nearly identical to those at Veracruz and Acapulco at the same elevation. The soundings at 06:00 UTC, for a time period unavailable to Whiteman et al. (2000), provided evidence that while most cooling occurred on average between 00:00 and 06:00 UTC, the basin was still somewhat warmer than the surrounding free atmosphere at the same elevation at 06:00 UTC.

The potential temperature and specific humidity profiles were averaged between 1 and 20 March and 21-31 March to determine differences in the heating of the central plateau before and after the second Norte, as shown in Fig. 16. After $21 \mathrm{March}$, potential temperatures decreased and specific humidities increased over both Mexico City and Veracruz as a result of the third and strongest Norte. During the drier and warmer period prior to the second Norte, the average boundary layer depth over Mexico City was about $500 \mathrm{~m}$ at 18:00 UTC. After the second Norte, the vertical potential temperature gradient between 3 and $5 \mathrm{~km}$ m.s.l. deceased significantly. During the late afternoon at 00:00 UTC, the average boundary layer potential temperatures were $4-5 \mathrm{~K}$ cooler and the mixed layer depth was about $1 \mathrm{~km}$ lower after the second Norte. A capping inversion between 5 and $5.5 \mathrm{~km}$ m.s.l. often formed during the night by 12:00 UTC after the second Norte. The specific humidity at Veracruz did not change significantly after the second Norte below about $2 \mathrm{~km}$ m.s.l.; however the average specific humidity increased by as much as $3-4 \mathrm{~g} \mathrm{~kg}^{-1}$ from the height of the plateau up to $7 \mathrm{~km}$ m.s.l. at both Veracruz and Mexico City. The rawinsonde measurements suggest that the changes in humidity occurred in the entire region and that the synoptic conditions after the second Norte altered the growth of the CBL and the near-surface stability over the basin. 

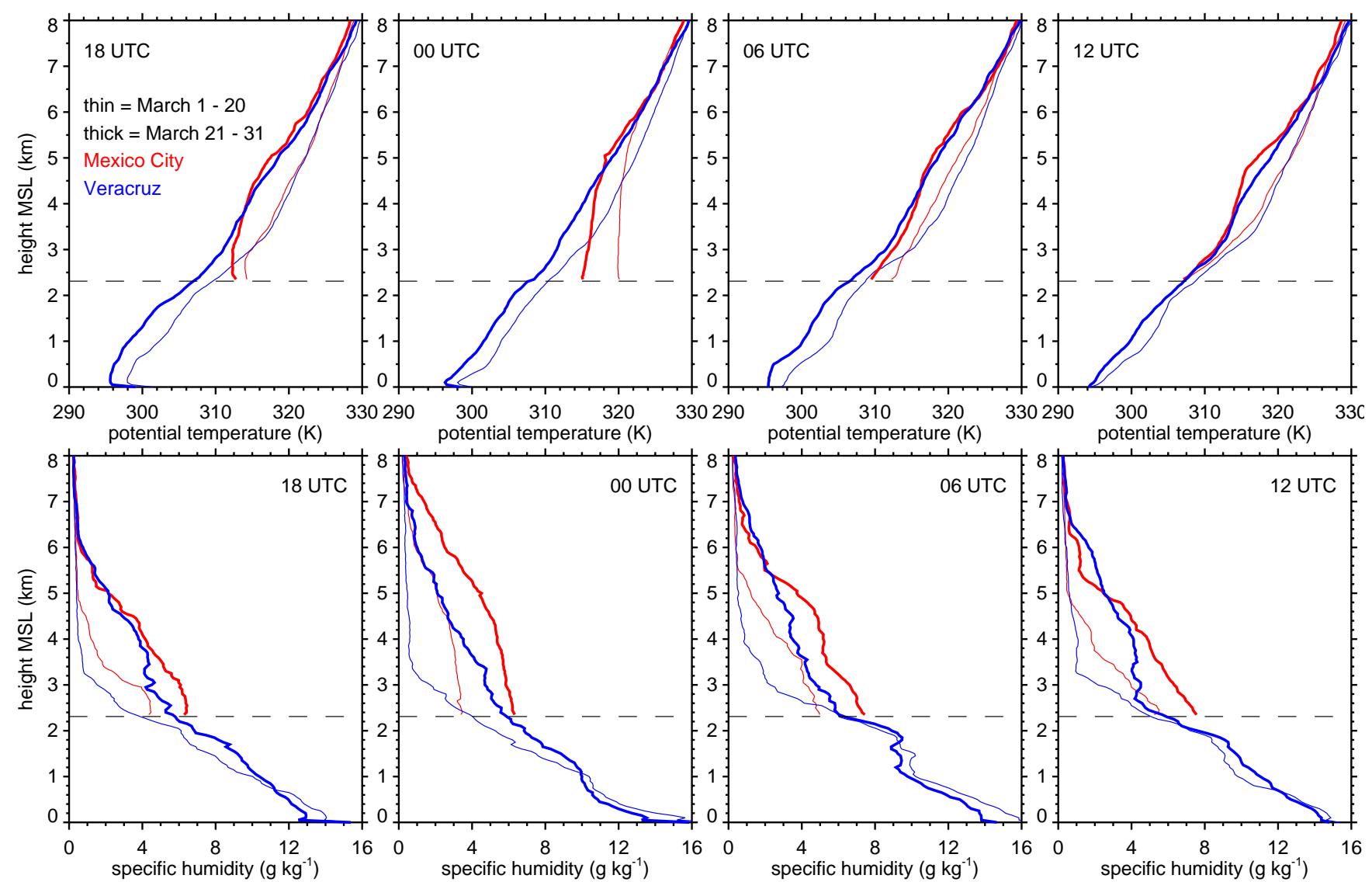

Fig. 16. Same as Fig. 15, except average potential temperature and specific humidity profiles before and after the second Norte at Mexico City and Veracruz. Thin and thick lines denote 1-20 March and 21-31 March periods, respectively.

A similar analysis was performed by averaging the rawinsonde profiles among three groups: those before the first Norte, those between the first and second Norte, and those after the second Norte. The resulting profiles showed a slight decrease in potential temperatures and increase in specific humidity after the first Norte (not shown), but that the largest changes occurred after the second and third Nortes.

High-pressure systems, weak synoptic forcing in the subtropics, and the horizontal temperature gradients over the central Mexican plateau (Figs. 15 and 14) are favorable for the development of local and regional thermally-driven flows (e.g. Bossert, 1997; Doran and Zhong, 2000; Whiteman et al., 2000) in the vicinity of Mexico City that affect the transport and mixing of pollutants. However, the local and regional winds will be suppressed when the synoptic forcing is sufficiently strong.

Wind profiler measurements at $\mathrm{T} 0$ and $\mathrm{T} 1$ are shown in Fig. 17 to indicate how often the diurnal thermally-driven winds over the central plateau (i.e. Fig. 1) are affected by the synoptic-scale forcing. There were two multi-day periods at T0 and T1 in which neither the near-surface nor the upper-level wind directions at 400 and $1500 \mathrm{~m}$ a.g.l., respec- tively, exhibited diurnal variations with strong vertical wind shears and were both similar to the $500-\mathrm{hPa}$ wind directions (Fig. 4). The strongest 500-hPa wind speeds during March occurred during these periods. The first period was between 9 and 11 March when the 500-hPa winds were southwesterly, and the second period was between 18 and 20 March when the 500-hPa winds were southerly. While the wind directions at $\mathrm{T} 0$ and $\mathrm{T} 1$ during the second period were very similar, wind directions at $\mathrm{T} 0$ and $\mathrm{T} 1$ occasionally differed by as much as 80 degrees during the first period. This suggests that an interaction of the ambient wind direction and the mountain ranges surrounding Mexico City may affect the extent of vertical coupling of the basin and synoptic winds. The wind directions at $1500 \mathrm{~m}$ a.g.l. at T0 generally exhibit more temporal variability than at $\mathrm{T} 1$, indicating that the basin topography affects the vertical wind structure to a greater extent over the city than over the more open terrain surrounding T1.

The radar wind profiler measurements in Fig. 17 show that there were many periods favorable for the transport of pollutants from Mexico City towards the northeast to the T1 and T2 sampling sites, as indicated by wind directions between 
(a) T1 radar wind profiler

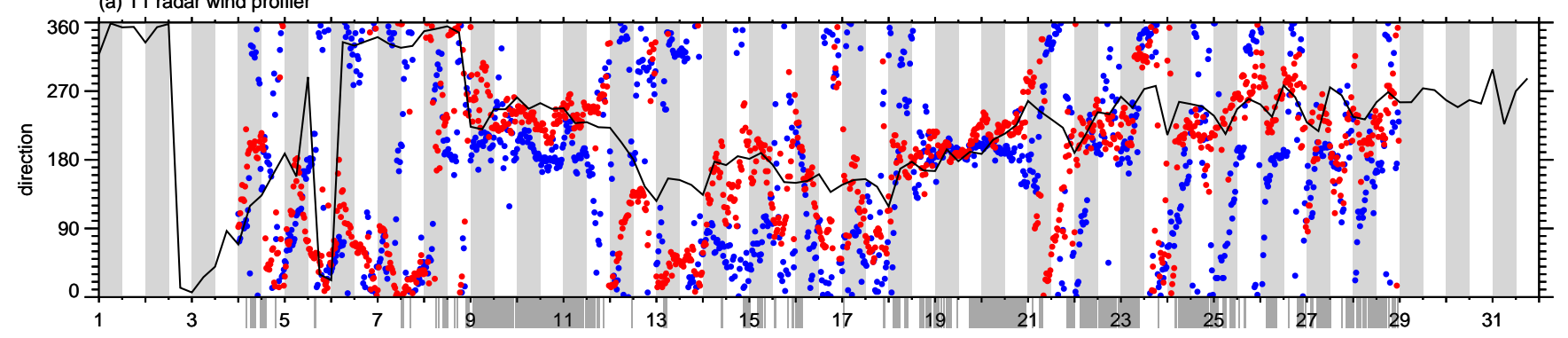

(b) T0 radar wind profiler

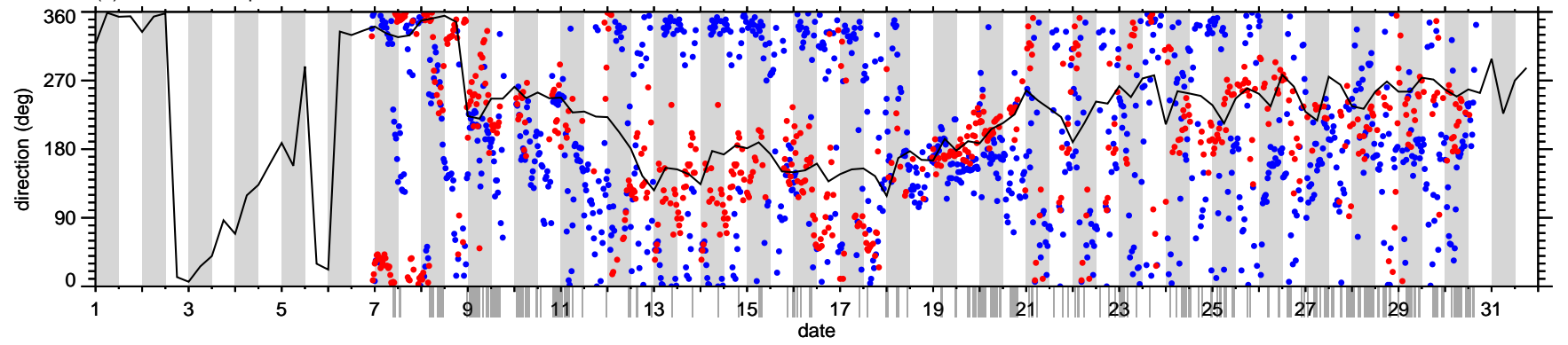

Fig. 17. Wind direction measured by radar wind profiles at the $400 \mathrm{~m}$ (blue dots) and $1500 \mathrm{~m}$ (red dots) a.g.l. range gates at the (a) T1 and (b) T0 sites. Black line denotes the $500 \mathrm{hPa}-$ level wind speed and direction from the GFS grid point closed to Mexico City and gray shading denotes nighttime periods. Gray shading along the x-axis denotes periods with directions between 195 and 255 degrees that are favorable for transport from Mexico City to the T1 and T2 sampling sites.

195 and 255 degrees. The periods in which the winds were within this range at $\mathrm{T} 1$ are also similar to the periods obtained from the Mexico City rawinsondes as shown in Fig. 4. However, the periods favorable for northeast transport at $\mathrm{T} 0$ were significantly shorter. The local winds near the surface, especially those within the basin, were obviously more complex than indicated by routine synoptic observations. Some of the differences between Figs. 4 and 17 result from the rawinsonde sampling interval every $6 \mathrm{~h}$ and the profiler sampling period of 30-min.

While increases in trace gases and aerosols measured at $\mathrm{T} 1$ and T2 will also indicate when transport from Mexico City occurred, dilution of the Mexico City plume and transport from other pollutant sources will complicate the interpretation of chemistry data. Initial analyses (J. C. Doran, personal communication) indicated that it was often difficult to attribute small increases in black carbon and organic carbon to the Mexico City plume. High-resolution models that are constrained by meteorological measurements and coupled with dispersion models will be needed to adequately describe the transport pathways and dilution by vertical mixing.

A more detailed analysis of boundary layer properties measured by the radar wind profilers, radiosondes, and lidars at the T0, T1, and T2 sites as well as an analysis of how localscale circulations within the Valley of Mexico affect pollutant transport will be the subject of up-coming papers.

\section{Transport}

A series of tracer simulations were performed using the WRF-chem model (Grell et al., 2005; Fast et al., 2006) for March 1997, 2001, 2004, 2005, and 2006 to 1) determine whether the synoptic conditions observed during March 2006 were typical or anomalous and 2) illustrate the large-scale transport pathways. Three domains were employed, with the outer domain encompassing most of Mexico and the surrounding ocean with a grid spacing of $22.5 \mathrm{~km}$, a second domain encompassing central Mexico with a grid spacing of $7.5 \mathrm{~km}$, and a third domain encompassing the Mexico City basin and areas to the northeast with a grid spacing of $2.5 \mathrm{~km}$. The model was run in a tracer mode that simulated the emission and transport of carbon monoxide (CO) with no chemical reactions. The emission rates of $\mathrm{CO}, e_{-} \mathrm{CO}$, from Mexico City were based on a 1998 inventory. Since no estimates were available on regional scales outside of the basin, the total $\mathrm{CO}$ emission rates for cities of 100000 people or more were based on population such that

$e_{-} \mathrm{CO}_{i}=e_{-} \mathrm{CO}_{\mathrm{MC}} \frac{\text { population }_{i}}{\text { population }_{\mathrm{MC}}}$

where MC stands for Mexico City and $i$ is the index for each city. Since Mexico City is by far the largest urban area, it was also the largest $\mathrm{CO}$ source.

The "footprint" of the $\mathrm{CO}$ plume during the entire month for each year is shown in Fig. 18. The footprint, FP, was 

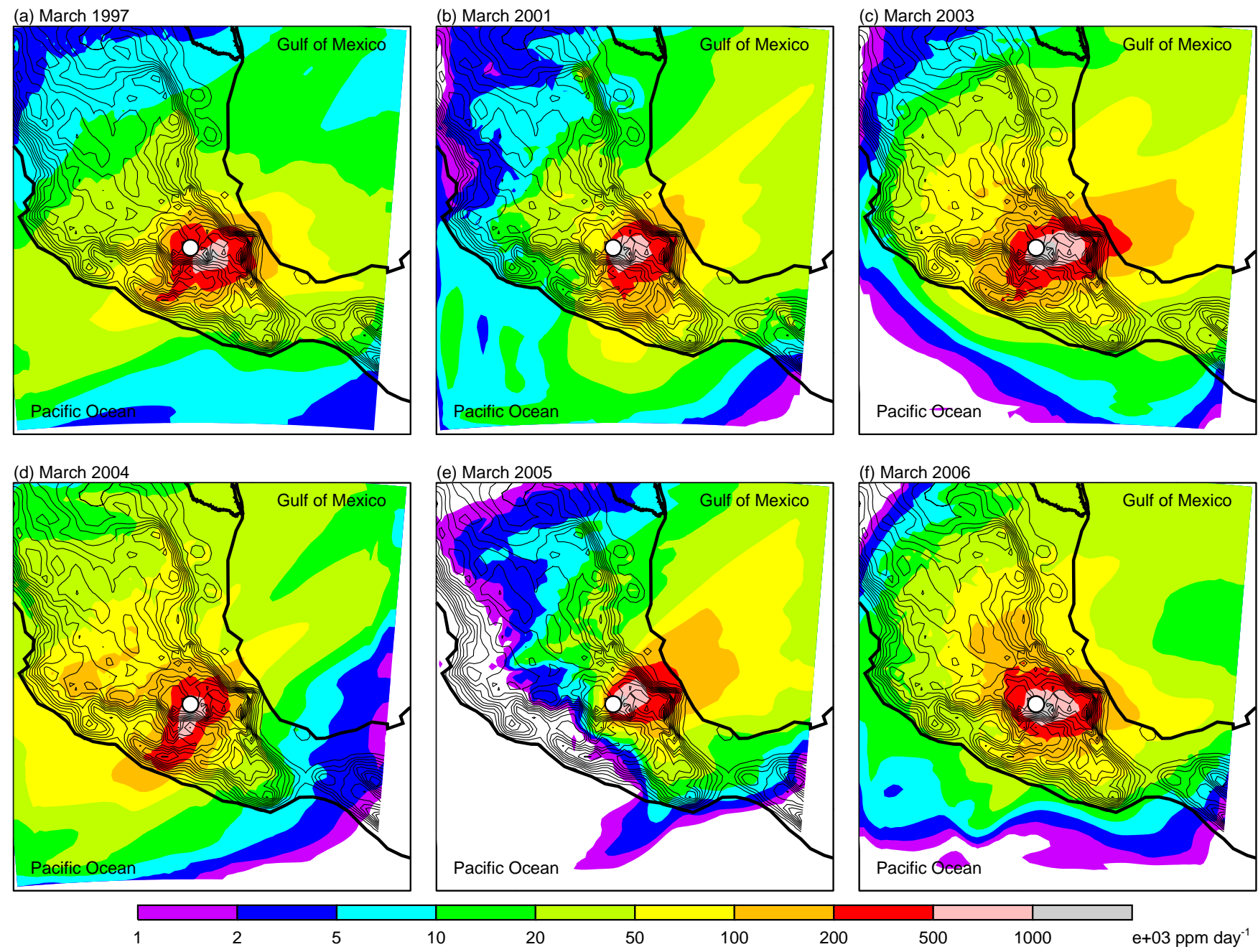

Fig. 18. The "footprint" of CO over Mexico averaged between 4.0 and $6.0 \mathrm{~km}$ m.s.l. obtained from WRF-chem tracer simulations for six March periods. Black contours denote topography and white dot denotes Mexico City.

obtained using the following relationship:

$F P(x, y)=\frac{1}{n t} \sum_{l=1}^{n t} \sum_{k=1}^{n z} C(x, y, k, l) \Delta z$, for

$4 \leq z \leq 6 \mathrm{~km} \mathrm{~m}$.s.l.

where $\mathrm{x}$ and $\mathrm{y}$ are the horizontal spatial locations, $C$ is the mixing ratio of $\mathrm{CO}, \Delta z$ is the vertical grid spacing, $n z$ is the number of vertical levels, and $n t$ is the number of hours during the simulation period. The largest values of FP denote regions where the Mexico City plume passed through most frequently. The distribution of FP between 2.5 and $4 \mathrm{~km} \mathrm{m.s.l.}$ was similar to the patterns shown in Fig. 18.

A common feature among five of the six simulations was the existence of two branches: one extending to the northeast over the Gulf of Mexico and the other extending to the southwest over the Pacific Ocean. The horizontal extent of these branches varied from year to year. The branch extending over the Gulf of Mexico was associated with high- pressure systems located east of Mexico City that produced transport towards the northeast (e.g. Fig. 3j). High-pressure systems located west of Mexico City that produced transport to the southwest were associated with the branch extending over the Pacific Ocean (e.g. Fig. 3a). The synoptic conditions during 1997 (Fig. 18a) and 2004 (Fig. 18d) frequently transported Mexico City CO over the Pacific Ocean, but the synoptic conditions during 2001 (Fig. 18b), 2003 (Fig. 18c), and 2006 (Fig. 18f) were not as favorable for transport towards the west. Transport towards the southwest did not occur at all at this altitude during 2005 (Fig. 18e) because a series of strong troughs propagated over Mexico the entire month; thus, March 2005 was most unlike the other periods. March of 2001, 2003, and 2004 had more CO transported towards the northeast over the Gulf of Mexico than during 2006. Although additional March periods need to be simulated to better establish a climatology of regional and long-range transport from Mexico City, the tracer analyses suggests that the synoptic conditions during March 2006 were not unusual. 

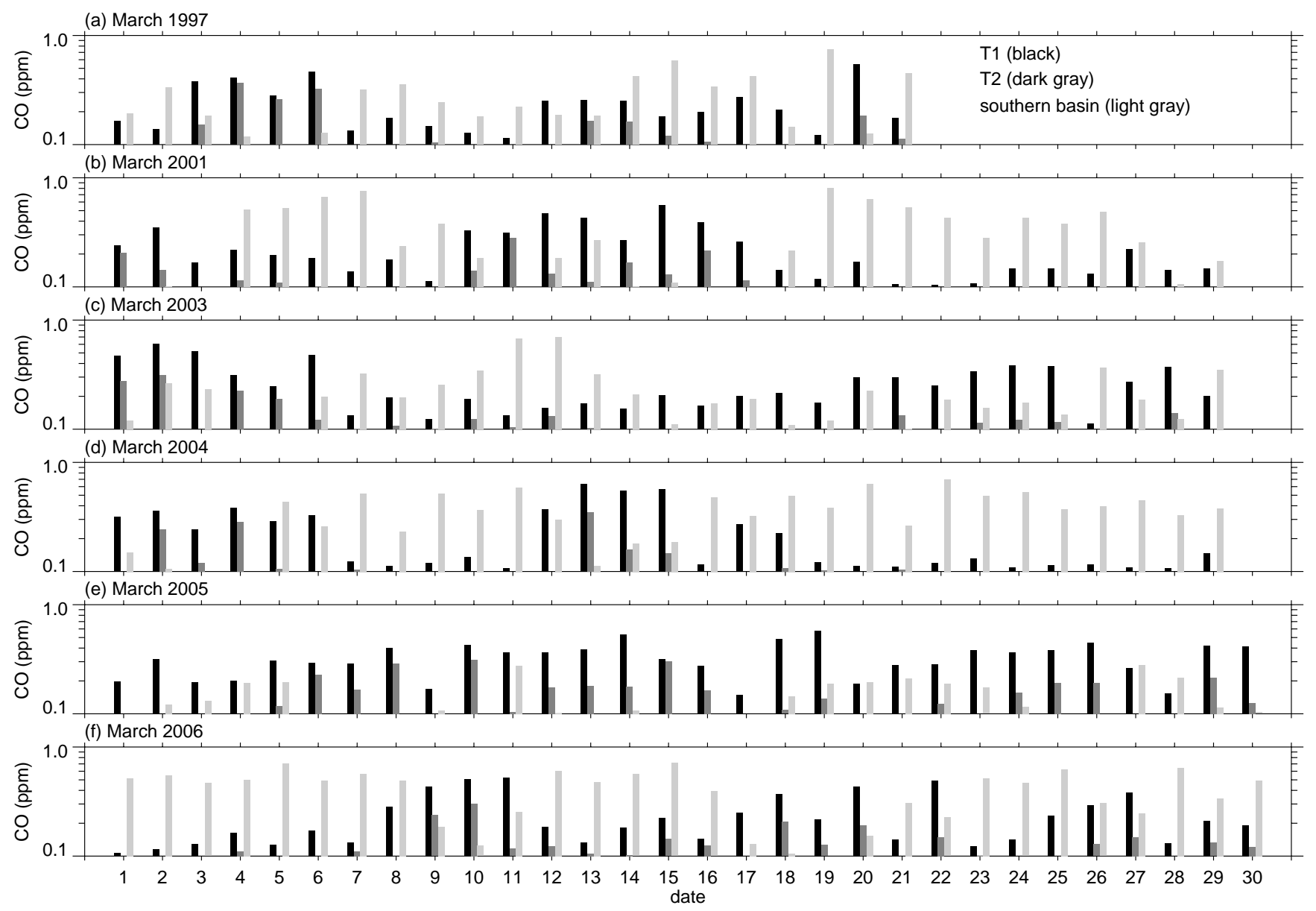

Fig. 19. Daily afternoon CO concentrations simulated by WRF-chem and averaged between 18:00 and 00:00 UTC over the T1 (black), T2 (dark gray), and Santa Ana (light gray) sites. Santa Ana located in the southern basin (Fig. 2b).

Because the third domain resolved the local circulations in the vicinity of Mexico City, we also quantified the periods in which Mexico City CO was transported over the T1 and T2 sampling sites. Shown in Fig. 19 are the daily afternoon surface simulated $\mathrm{CO}$ mixing ratios averaged between 18 and 00:00 UTC over the T1, T2, and Santa Ana sites (Fig. 2b). Not surprisingly, simulated $\mathrm{CO}$ mixing ratios above the background concentration $(80 \mathrm{ppb})$ were produced over T1 nearly every day because of its proximity to Mexico City and local emission sources. Days with relatively large concentrations at both $\mathrm{T} 1$ and $\mathrm{T} 2$ (with concentrations smaller at $\mathrm{T} 2$ as a result of dilution farther downwind) were associated with periods of upper-level southwesterly winds. March 2006 had about the same number of days with transport towards the northeast as the other years, except for 2005, when the strong westerly synoptic winds transported CO more frequently over T1 and T2. As expected, transport towards Santa Ana was low when the conditions were favorable for transport to $\mathrm{T} 1$ and $\mathrm{T} 2$.
The model suggests that 9-10 March and 18-20 March were periods with the most direct transport between $\mathrm{T} 0$ and T2. This is consistent with the simple analyses of the 700 and $500 \mathrm{hPa}$ winds shown in Fig. 4. The lower concentrations during 11, 12, 15, 16, 22, 26, 27, 29, and 30 March 2006 indicate periods less favorable for transport directly towards the northeast. A visual inspection of the spatial evolution of $\mathrm{CO}$ indicated that on these days the center of the Mexico City plume was located east or west of $\mathrm{T} 1$ and $\mathrm{T} 2$. The model also showed that strong synoptic forcing with southwesterly winds was needed to produce relatively large mixing ratios at $\mathrm{T} 2$. Weaker synoptic forcing would enable the local thermally-driven circulations to develop and dilute the plume before it could be transported towards $\mathrm{T} 2$.

Measurements and large-scale analyses of the winds over the central Mexican plateau, including those presented in Figs. 3, 4, 17, and 18, were used to determine which days during March 2006 were favorable for the transport of pollutants from Mexico City to the T1 and T2 sampling sites for each day as listed in Table 3. The aircraft flight days are 
Table 3. MILAGRO research aircraft flight days and the associated upper-level wind directions and likelihood of T0-T1-T2 sampling.

\begin{tabular}{|c|c|c|c|c|c|c|c|c|}
\hline March & DC8 & C130 & $\mathrm{J} 31$ & B200 & G1 & USFS & $500 \mathrm{hPa}$ wind direction & T0-T1-T2 transport \\
\hline 1 & & & & & & & $\mathrm{~N}$ & Unlikely \\
\hline 2 & & & & & & & $\mathrm{~N}$ & Unlikely \\
\hline 3 & & & $x$ & $x$ & $x$ & & $\mathrm{NE}$ & Unlikely \\
\hline 4 & $x$ & $x$ & & & & $x$ & SE & Unlikely \\
\hline 5 & & & $x$ & & & & $\mathrm{~W}$ & Unlikely \\
\hline 6 & & & $x$ & $x$ & $x$ & $x$ & NW & Unlikely \\
\hline 7 & & & & $x$ & $\times$ & & NW & Unlikely \\
\hline 8 & & $\times$ & $x$ & $\times$ & & $x$ & NW & Possible \\
\hline 9 & $x$ & & & $x$ & $\times$ & $x$ & SW & Likely \\
\hline 10 & & $x$ & $x$ & $x$ & & & SW & Likely \\
\hline 11 & $x$ & & $x$ & & & $x$ & SW & Likely \\
\hline 12 & $x$ & $\times$ & $x$ & $\times$ & & $x$ & $\mathrm{~S}$ & Likely \\
\hline 13 & & & $x$ & $x$ & & & $\mathrm{~S}$ & Unlikely \\
\hline 14 & & & & & & & $S$ & Unlikely \\
\hline 15 & & & $x$ & $x$ & $x$ & & $\mathrm{~S}$ & Unlikely \\
\hline 16 & $x$ & $x$ & & & & & $\mathrm{~S}$ & Unlikely \\
\hline 17 & & & $x$ & & & $x$ & $\mathrm{~S}$ & Possible \\
\hline 18 & & $\times$ & $x$ & & $x$ & $x$ & $\mathrm{~S}$ & Likely \\
\hline 19 & $x$ & $\times$ & $x$ & & $\times$ & & SW & Likely \\
\hline 20 & & & $x$ & & $\times$ & & SW & Likely \\
\hline 21 & & & & & & & SW & Likely \\
\hline 22 & & $x$ & & & $x$ & $x$ & SW & Likely \\
\hline 23 & & $x$ & & & & & W & Possible \\
\hline 24 & & & & & & & W & Likely \\
\hline 25 & & & & & & $\times$ & W & Likely \\
\hline 26 & & & & & $x$ & & W & Possible \\
\hline 27 & & & & $x$ & $\times$ & $\times$ & W & Possible \\
\hline 28 & & $\times$ & & $x$ & & $x$ & W & Possible \\
\hline 29 & & $x$ & & $x$ & & $x$ & $\mathrm{~W}$ & Possible \\
\hline 30 & & & & & & & W & Likely \\
\hline
\end{tabular}

included to indicate which flights occurred during likely periods of transport towards the northeast. Chemistry data from $\mathrm{T} 1$ and T2 will quantify whether the meteorological transport actually happened.

While T1 was located just outside the Mexico City metropolitan area, the chemical measurements could also be influenced by local urban sources and by emissions along the major highway between Mexico City and Pachuca located less than a kilometer to the east. The local sources would complicate the signal of the Mexico City plume. Conversely, $\mathrm{T} 2$ is located in a remote location with no significant urban sources in the vicinity of the site. If the Mexico City plume is sufficiently dilute, chemistry measurements may also be indicative of long-range transport, biomass burning, and dust. In contrast to Fig. 18, the WRF-chem simulations produced an accumulation of CO over the slopes of the Sierra Madre Oriental below $2.5 \mathrm{~km}$ m.s.l. as a result of converging southwesterly flow over the plateau and easterly up-slope flow over the plateau edge. This feature was also produced by simulations of the MCMA-2003 field experiment (de Foy et al., 2006b). Aircraft measurements during MILAGRO can be used to quantify the spatial extent and residence time of pollutants that accumulate in this region.

\section{Conclusion}

We have discussed the rationale for the meteorological measurement and modeling strategy designed prior to the MILAGRO field campaigns. In-situ and remote-sensing instrumentation was deployed to obtain measurements of wind, temperature, and humidity profiles in the boundary layer and free atmosphere at four primary sampling sites in central Mexico. Several models were run operationally during the field campaign to provide forecasts of the local, regional, and synoptic meteorology as well as the predicted location of the Mexico City pollutant plume for aircraft flight planning purposes. The performance of MILAGRO models in predicting the local and regional meteorology and the location and concentration of Mexico City pollutants will be subjects of other studies. Here, we employ field measurement, 
operational measurements, and large-scale analyses to describe the evolving large-scale meteorological conditions during March 2006 that affect atmospheric chemistry over Mexico.

Three cold surges occurred during the second half of the month. The first two cold surges, which began on 14 and 21 March, were relatively weak with near-surface northerly wind speeds less than $15 \mathrm{~m} \mathrm{~s}^{-1}$ at Veracruz that lasted less than a day. The third cold surge started on 23 March and lasted two days with peak near-surface wind speeds as high at $25 \mathrm{~m} \mathrm{~s}^{-1}$ at Veracruz. While the northerly winds observed over the central plateau were significantly weaker and shorter in duration than those along the coast, the cold surges increased the humidity and decreased the stability of the lower atmosphere, leading to increased convection and precipitation over the central plateau. The varying synoptic conditions likely affected the photochemistry, vertical mixing, and scavenging of pollutants downwind of Mexico City as well.

Therefore, the cold surges are used to define three regimes that characterize the overall ambient meteorological conditions during the field campaign: the first regime prior to 14 March, the second regime between 14 and 23 March, and the third regime after 23 March. During the first regime, mostly sunny and dry conditions with periods of cirrus were observed over most of central Mexico. The beginning of the second regime was characterized by a sharp increase in humidity and the development of late afternoon convection associated with the passage of the weak cold surge on 14 March. Over the next several days, the atmosphere over the central plateau became drier so that deep convection gradually diminished. The third regime began with the strongest cold surge and led to humidity, afternoon convection, and precipitation over the central plateau that was higher than during the second regime. The frequency and intensity of fires, as determined by satellite measurements, also diminished significantly after the third cold surge.

The complex terrain surrounding Mexico City produces local and regional circulations that control short-range transport; however, the synoptic conditions modulate the thermally-driven circulations. On several days the nearsurface flow is coupled to the ambient winds aloft, particularly during 9-11 and 18-20 March when the strongest wind speeds at $500 \mathrm{hPa}$ were observed. The processes associated with the local and regional circulations and their interaction with the synoptic conditions as observed by MILAGRO meteorological instrumentation, as well as the impact of transport and mixing processes on the evolution of trace gases and aerosols, need to be investigated in more detail by future studies. The results of a series of tracer transport simulations using the WRF-chem model for multiple March periods indicated that the long-range transport patterns downwind of Mexico City during March 2006 were not unusual.

Acknowledgements. We would like to thank W. Shaw and M. Pekour (Pacific Northwest National Laboratory), J. Walters
(University of Alabama - Huntsville), and meteorologists at SMN, and other participants for providing data used in this study. J. Meitin (NCAR) and his team for set up the MILAGRO field catalog and coordinated the launching of supplemental rawinsondes by SMN personnel. E. Campbell (University of Iowa) and others contributed their time forecasting for a portion of the field campaign period. The MILAGRO field campaigns were supported by the DOE, NSF, NASA, USDA Forest Service, and by several Mexican research agencies. This research was supported by the U.S. DOE's Atmospheric Sciences Program of the Office of Biological and Environmental Research under Contract DE-AC06-76RLO 1830 at PNNL. Pacific Northwest National Laboratory is operated for the U.S. DOE by Battelle Memorial Institute. The National Center for Atmospheric Research is operated by the University Corporation for Atmospheric Research under sponsorship by the NSF.

Edited by: J. Gaffney

\section{References}

Baumgardner, D., Raga, G. B., Kok, G., Ogren, J., Rosas, I., Baez, A., and Novakov, T.: On the evolution of aerosol properties at a mountain site above Mexico City, J. Geophys. Res., 105, $22243-$ $22253,2000$.

Baumgardner, D., Raga, G. B., and Mulhia, A.: Evidence for the formation of $\mathrm{CCN}$ by photochemical processes in Mexico City, Atmos. Environ., 38, 357-367, 2004.

Bey, I., Jacob, D. J., Yantosca, R. M., Logan, J. A., Field, B., Fiore, A. M., Li, Q., Liu, H., Mickley, L. J., and Schultz, M.: Global modeling of tropospheric chemistry with assimilated meteorology: Model description and evaluation, J. Geophys. Res., 106, 23 073-23 096, 2001.

Bossert, J. E.: An investigation of flow regimes affecting Mexico City region, J. Appl. Meteorol., 36, 119-140, 1997.

Campbell, J. R., Hlavka, D. L., Welton, E. J., Flynn, C. J., Turner, D. D., Spinhirne, J. D., and Scott, V. S.: Full-time eye-safe cloud and aerosol lidar observation at atmospheric radiation Measurement program sites: Instruments and data processing, J. Atmos. Ocean. Technol., 19, 431-442, 2002.

Carmichael, G. R., Tang, Y., Kurata, G., Uno, L., Streets, D., Woo, J.-H., Huang, H., Yienger, J., Lefer, B., Shetter, R., Blake, D., Atlas, E., Fried, A., Apel, E., Eisele, F., Cantrell, C., Avery, M., Barrick, J., Sachse, G., Brune, W., Sandholm, S., Kondo, Y., Singh, H., Talbot, R., Bandy, A., Thorton, D., Clarke, A., and Heikes, B.: Regional-scale chemical transport modeling in support of the analysis of observations obtained during the TRACE-P experiment, J. Geophys. Res., 108(D21), 8823, doi:101029/2002JD003117, 2003.

Collins, C. O. and Scott, S. L.: Air pollution in the valley of Mexico, Geogr. Rev., 2, 119-133, 1993.

De Foy, B., Caetano, E., Magana, V., Zitacuaro, A., Cardenas, B., Retama, A., Ramos, R., Molina, L. T., and Molina, M. J.: Mexico city basin wind circulation during the MCMA-2003 field campaign, Atmos. Chem. Phys., 5, 2267-2288, 2005, http://www.atmos-chem-phys.net/5/2267/2005/.

De Foy, B., Clappier, A., Molina, L. T., and Molina, M. J.: Distinct wind convergence patterns in the Mexico City basin due to the interaction of the gap winds with the synoptic flow, Atmos. Chem. Phys., 6, 1249-1265, 2006a. 
De Foy, B., Varela, J. R., Molina, L. T., and Molina, M. J.: Rapid ventilation of the Mexico City basin and regional rate of the urban plume, Atmos. Chem. Phys., 6, 2321-2335, $2006 \mathrm{~b}$.

Doran, J. C. and Zhong, S.: Thermally driven gap winds in the Mexico City basin, J. Appl. Meteorol., 39, 1330-1340, 2000.

Doran, J. C., Abbott, S., Archuleta, J., Bian, X., Chow, J., Coulter, R. L., de Wekker, S. F. J., Edgerton, S., Elliot, S., Fernandez, A., Fast, J. D., Hubbe, J. M., King, C., Langley, D., Leach, J., Lee, J. T., Martin, T. J., Martinez, S., Apam, D., Martinez, J. L., Mercado, G., Mora, V., Mulhearn, M., Pena, J. L., Petty, R., Porch, W., Russel, C., Salas, R., Shannon, J. D., Shaw, W. J., Sosa, G., Tellier, L., Templeman, B., Watson, J. G., White, R., Whiteman, C. D., and Wolfe, D.: The IMADA-AVER boundarylayer experiment in the Mexico City area, Bull. Amer. Meteorol. Soc., 79, 2497-2508, 1998.

Draxler, R. R. and Rolph, G. D.: HYSPLIT (HYbrid Single-Particle Lagrangian Integrated Trajectory) Model access via NOAA ARL READY Website (http://www.arl.noaa.gov/ready/hysplit4.html), NOAA Air Resources Laboratory, Silver Spring, MD, 2003.

Edgerton, S. A., Arriaga, J. L., Archuleta, J., Bian, X., Bossert, J. E., Chow, J. C., Coulter, R. L., Doran, J. C., Doskey, P. V., Elliot, S., Fast, J. D., Gaffney, J. S., Guzman, F., Hubbe, J. M., Lee, J. T., Malone, E. L., Marley, N. A., McNair, L. A., Neff, W., Ortiz, E., Petty, R., Ruiz, M., Shaw, W. J., Sosa, G., Vega, E., Watson, J. G., Whiteman, C. D., and Zhong, S.: Particulate air pollution in Mexico City: A collaborative research project, J. Air Waste Manage. Assoc., 49, 1221-1229, 1999.

Fast, J. D. and Zhong, S.: Meteorological factors associated with inhomogeneous ozone concentrations within the Mexico City basin, J. Geophys. Res., 103, 18 927-18 946, 1998.

Fast, J. D., Gustafson Jr., W. I., Easter, R. C., Zaveri, R. A., Barnard, J. C., Chapman, E. G., and Grell, G. A.: Evolution of ozone, particulates, and aerosol direct forcing in an urban area using a new fully-coupled meteorology, chemistry, and aerosol model, J. Geophys. Res., 111, D21305, doi:10.1029/2005JD006721, 2006.

Garfias, J. and Gonzalez, R.: Air quality in Mexico City, in: The Science of Global Change: The Impact of Human Activities on the Environment, Am. Chem. Soc., Washington D.C., pp 149$161,1992$.

George, J. J.: Weather and Forecasting for Aeronautics, Academic Press, 673 pp, 1960.

Grell, G. A., Dudhia, J., and Stauffer, D. R.: A description of the fifth generation Penn State/NCAR mesoscale model, available from the National Center for Atmospheric Research, P.O. Box 3000, Boulder, CO 80303, NCAR Tech. Note 398+1A, 122 pp, 1993.

Grell, G. A., Peckham, S. E., Schmitz, R., McKeen, S. A., Frost, G., Skamarock, W. C., and Eder, B.: Fully coupled "online" chemistry within the WRF model, Atmos. Environ., 39, 6957-6975, 2005.

Horowitz, L. W., Walters, S., Mauzerall, D. L., Emmons, L. K., Rasch, P. J., Granier, C., Tie, X., Lamarque, J.-F., Schultz, M. G., Tyndall, G. S., Orlando, J. S., and Brasseur, G. P.: A global simulation of tropospheric ozone and related tracers: Description and evaluation of MOZART, version 2, J. Geophys. Res., 108(D24), 4783, doi:10.1029/2002JD002853, 2003.

Jáuregui, E.: Local wind and air pollution interaction in the Mexico basin, Atmósfera, 1, 131-140, 1988.

Jáuregui, E.: Heat island development in Mexico City, Atmos. En- viron., 31, 3821-3831, 1997.

Jáuregui, E.: El Clima de la Ciudad de México, Publisher Instituto de Geografia - UNAM, 129 pp. ISBN: 968-856-819-8 (in Spanish), 2000.

Jáuregui, E. and Luyando, E.: Global radiation attenuation by air pollution and its effects on the thermal climate of Mexico City, Intl. J. Climatol., 19, 683-694, 1999.

Jáuregui, E. and Romales, E.: Urban effects of convective precipitation in Mexico City, Atmos. Environ., 30, 3383-3389, 1996.

Jazcilevich, A. D., Garcia, A. R., and Ruiz-Suarez, L.: A study of air flow patterns affecting pollutant concentrations in the central region of Mexico, Atmos. Environ., 37, 183-193, 2003.

Jazcilevich, A. D., Garcia, A. R., Caetano, E.: Locally induced surface air confluence by complex terrain and its effect on air pollution in the valley of Mexico, Atmos. Environ., 39, 5481-5489, 2005.

Johnson, K. S., de Foy, B., Zuberi, B., Molina, L. T., Molina, M. J., Tie, Y., Laskin, A., and Shutthanandan, V.: Aerosol composition and source apportionment in the Mexico City metropolitan area with PIXE/PESA/STIM and multivariate analysis, Atmos. Chem. Phys., 6, 4591-4600, 2006,

http://www.atmos-chem-phys.net/6/4591/2006/.

Karan, H. and Knupp, K.: Mobile Integrated Profiler System (MIPS) observations of low-level convergent boundaries during IHOP, Mon. Wea. Rev., 134, 92-112, 2006.

Lauer, W. and Klaus, D.: The thermal circulation of the central Mexico meseta region within the influence of the trade winds, Arch. Meteorol. Geophys. Bioklimatol., 23, 343-366, 1975.

Long, C. R., Ackerman, T. P., Gaustad, K. L., and Cole, J. N. S.: Estimations of fractional sky cover from broadband shortwave radiometer measurements, J. Geophys. Res., 111, D11204, doi:10.1029/2005JD006475, 2006.

McKeen, S., Wilczak, J., Grell, G., Djalalova, I., Peckham, S., Hsie, E. Y., Gong, W., Bouchet, V., Menard, S., Moffet, R., McHenry, J., McQueen, J., Tang, Y., Carmichael, G.R., Pagowski, M., Chan, A., Dye, T., Frost, G., Lee, P., and Mathur, R.: Assessment of an ensemble of seven real-time ozone forecasts over eastern North America during the summer of 2004, J. Geophys. Res., 110, D21, doi:10.1029/2005JD005858, 2005.

Mosino Aleman, P. A. and Garcia, E.: The Climate of Mexico, in: Climates of North America, edited by: Bryson, R. A. and Hare, F. K., vol. 11 of World Survey of Climatology, chap. 4, pp. 345404, Elsevier Scientific Publishing Company, 1974.

Oke, T. R., Spronken-Smith, R. A., Jáuregui, E., and Grimmond, C. S. B.: The energy balance of central Mexico City during the dry season, Atmos. Environ., 33, 3919-3930, 1999.

Pierce, R. B., Al-Saadi, J. A., Schaack, T., Lenzen, A., Zapotocny, T., Johnson, D., Kittaka, C., Buker, M., Hitchman, M. H., Tripoli, G., Fairlie, T. D., Olson, J. R., Natarajan, M., Crawford, J., Fishman, J., Avery, M., Browell, E. V., Creilson, J., Kondo, Y., and Sandholm, S. T.: Regiona air quality modeling system (RAQMS) predictions of the tropospheric ozone budget over east Asia, J. Geophys. Res., 108(D21), 8825, doi:10.1029/2002JD003176, 2003.

Raga, G. B., Baumgardner, D., Kok, G., and Rosas, I.: Some aspects of boundary layer evolution in Mexico City, Atmos. Environ., 1999, 5013-5021, 1999a.

Raga, G. B., Kok, G. I., Baumgarder, D., Baez, A., and Rosas, I.: Evidence for volcanic influence on Mexico City aerosols, Geo- 
phys. Res. Lett., 26, 1149-1152, 1999b.

Raga, G. B., Baumgardner, D., Castro, T., Martinez-Arroyo, A., and Navarro-Gonzalez, R.: Mexico City air quality: A qualitative review of gas and aerosol measurements (1960-2000), Atmos. Environ., 35, 4041-4058, 2001.

Shultz, D. M., Bracken, W. E., Bosart, L. E., Hakim, G. J., Bedrick, M. A., Dickinson, M. J., and Tyle, K. R.: The 1993 superstorm cold surge: Frontal structure, gap flow, and tropical impact, Mon. Wea. Rev., 125, 5-39, 1997.

Skamarock, W. C., Klemp, J. B., Dudhia, J., Gill, D. O., Barker, D. M., Wang, W., and Powers, J. G.: A description of the advanced research WRF version 2, NCAR Technical Note, NCAR/TN468+STR, 8 pp, 2005.

Steenburgh, J. W., Shultz, D. M., and Colle, B. A.: The structure and evolution of gap outflow over the Gulf of Tehuantepec, Mexico, Mon. Wea. Rev., 126, 2673-2691, 1998.
Stohl, A., Forster, C., Frank, A., Siebert, P., and Wotawa, G.: Technical Note: The Lagrangian particle dispersion model FLEXPART version 6.2, Atmos. Chem. Phys., 5, 2461-2474, 2005, http://www.atmos-chem-phys.net/5/2461/2005/.

Vega, E., Reyes, E., Sanchez, G., Ortiz, E., Ruiz, M., Chow, J., Watson, J., and Edgerton, S.: Basic statistics of PM2.5 and PM10 in the atmosphere of Mexico City, Sci. Tot. Environ., 287, 167176, 2002.

Wiedinmyer, C., Quayle, B., Geron, C., Beloe, A., McKenzie, D., Zhang, X., O’Neill, S., and Klos Wynne, K.: Estimating emissions from fires in North America for air quality modeling, Atmos. Environ., 40, 3419-3432, 2006.

Whiteman, C. D., Zhong, S., Bian, X., Fast, J. D., and Doran, J. C.: Boundary layer evolution and regional-scale diurnal circulations over the Mexican basin, J. Geophys. Res., 105, 10 081-10 102, 2000 . 